Research Article

\title{
Foundation Treatment Assessment and Postconstruction Settlement Prediction of a Loess High Fill Embankment: A Case Study
}

\author{
Caihui Zhu $\mathbb{D}^{1},{ }^{1,2,3}$ Xiaosong Zhou $\mathbb{D}^{4},{ }^{4}$ and Songhe Wang $\mathbb{D}^{1,2,3}$ \\ ${ }^{1}$ State Key Laboratory of Eco-hydraulics in Northwest Arid Region, Xi'an University of Technology, Xi'an, China \\ ${ }^{2}$ Institute of Geotechnical Engineering, Xi'an University of Technology, Xi'an 710048, Shaanxi, China \\ ${ }^{3}$ Shaanxi Provincial Key Laboratory of Loess Mechanics, Xi'an University of Technology, Xi'an, China \\ ${ }^{4}$ China Jikan Research Institute of Engineering Investigastions and Design, Co., Ltd., Xi'an, China
}

Correspondence should be addressed to Caihui Zhu; anderth123@163.com and Songhe Wang; wangsonghe@xaut.edu.cn

Received 9 April 2020; Revised 21 October 2020; Accepted 24 October 2020; Published 12 November 2020

Academic Editor: Sara Amoroso

Copyright (c) 2020 Caihui Zhu et al. This is an open access article distributed under the Creative Commons Attribution License, which permits unrestricted use, distribution, and reproduction in any medium, provided the original work is properly cited.

The design of high fill embankments (HFEs) on the loess plateau requires proper foundation treatment methods and reasonable prediction of postconstruction settlement (PCS). In situ tests were carried out on a test section of the collapsible loess foundation of a high fill airport to assess the reinforcement effects of common treatment methods. Based on in situ monitored data, the spatial-temporal variations of the PCS of the HFE were investigated, with a simple empirical formula proposed for PCS prediction. The PCS increases linearly with the fill thickness, and the PCS rate varies exponentially with the fill rate. Two engineering recommendations were made to reduce differential PCS and water damage for the test site. The first is to combine the reinforcement methods to reduce PCS of the HFE, i.e., dynamic compaction for loess foundation with lower water content and gravel piles with stabilizers for that with higher water content. The second is to employ the dynamic compaction (DC), percussive compaction (PC), and vibration compaction (VC) to strengthen the fill to reach an average compaction degree above 0.93 and a water content close to the optimal.

\section{Introduction}

Northwest China is a mountainous area, with a growing demand for deep excavation and high fill projects, such as dams, airports, subgrades, and urban space construction, especially in the collapsible loess area [1]. Collapsible loess is a special soil with a loose structure and high porosity, and the shear strength of unsaturated loess is high and the compressibility is low. When it is soaked by water and is under a certain pressure, the soil structure will be destroyed quickly, resulting in large additional subsidence and a rapid decrease in strength [2]. These high fill projects bring new opportunities and challenges to the field of geotechnical engineering research. Fill technology of high embankments, foundation treatment methods, and postconstruction settlement (PCS) control are widely concerned issues. The prototype tests, in situ monitoring, numerical methods, laboratory tests, model tests, fuzzy theory, and analytical solutions have been used to study the PCS and control technology in high fill embankment (HFE) projects [3-11]). In situ tests and monitoring are of great significance for quickly obtaining construction control standards and the spatial-temporal deformation of such projects. The foundation soil and the high fill body are the two geological entities that constitute HFE projects; they need to be reinforced to achieve the design function.

In order to reduce the PCS of embankments, the stiffness of the high fill and foundation soil should be enhanced, and the bearing capacity of the soil should be increased. There are many techniques that are used to improve the stiffness and bearing capacity of the saturated clayey soil [12-21]. These techniques include soil removal and replacement, 
precompression or preloading, improvement, and stabilization. Rowe and Liu et al. [16] studied the reinforcement effects of a full-scale geosynthetic-reinforced, pile-supported embankment by using a fully coupled three-dimensional finite element method, which indicates the applicability of the proposed method in reducing the settlement at the subsoil surface. Reference [19] found that the pile spacing with the geosynthetic-reinforced method is the most sensitive factor influencing the maximum settlement of the subsoil. In recent decades, geotextile reinforcement and tirereinforced methods have been verified to improve the strength of the soil of embankments $[14,17]$. The deep mixed columns with cement-fly ash-gravel piles (CFGs) are also commonly used for ground improvement to treat the settlement of embankments [5, 13, 20, 22, 23].

The above methods are mostly used in soft soil foundations, some of which are available for foundation treatment in deep collapsible loess foundation in HFE projects. Wang et al. [24] performed a centrifugal model test with a geogrid-reinforced pile-raft-supported method considered in high-speed railways embankments on collapsible loess, and the proper value of the pile spacing was suggested. Mei et al. [15] reported that the dynamic compaction (DC) method can effectively improve the bearing capacity and eliminate the collapsibility of the loess foundation. Li et al. [12] proposed the explosive compaction technology for loess embankment settlement control. Zhu and Han et al. [21] suggested that the compaction technology, pile plate structure, effective drainage measures, and soil improvement with admixtures can be systematically adopted for collapsible loess foundations to reduce the engineering problems. For controlling the PCS of the HFE projects in loess regions, $\mathrm{Hu}$ et al. [3] suggested that the water content should be controlled within a range of $12 \%-14 \%$. Wang [24] proposed that the following methods could be used to decrease the PCS of fill embankments: using lightweight fill materials, enhancing the compaction degree of the fill materials, and increasing the pile length in the foundation soil. For predicting the PCS of fill embankment, the empirical method, numerical method, and in situ monitoring are widely used $[4,5,11,25]$. In previous studies, researchers proposed empirical formulas to estimate the crest PCS of the HFE [26-30]. The empirical formulas were shown in Table 1. They can be generally represented as

$$
S=a+\frac{b H^{c}}{E^{d}} e^{\left(-m / t^{n}\right)},
$$

where $S$ is the crest PCS of the fill body $(m), H$ is the fill height of the embankment $(m), t$ is the duration time of PCS (years), $E$ is the deformation modulus of the fill material $(\mathrm{MPa})$, and $a, b, c, d, m$, and $n$ are the empirical coefficients.

Equation (1) indicates that the PCS has nonlinear relationships with the fill height, the compression characteristics of the fill body, and the duration time. However, equation (1) does not consider the thickness and compression characteristics of the foundation soil, and it is used for self-weight settlement prediction of embankment fill. The settlement of foundation soil is not included in it.
The sources of PCS or its major components are currently not sufficiently clear from previous studies. Moreover, the effects of foundation treatment and fill process are not reasonably considered in PCS predictions. In this study, a test section of a high fill airport was taken as the study object (the purpose of fill construction is to reach an adequate level for an airfield and/or other structures related to airport construction). In situ tests of PCS were carried out to study the reinforcement effects of different treatment methods for the HFE. The proportions of the PCS of the foundation soil and the fill body in the total were explored. The relationship between the PCS and the fill height, fill rate, and the average compaction degree was analyzed, with an empirical formula of PCS considering different factors proposed and verified. Finally, combined with a case history of engineering problems caused by uneven PCS, the construction control standards for loess HFE were proposed.

\section{Engineering Background of HFE}

2.1. Project Description of Lvliang Airport. Lvliang Airport is located over the loess ridge in the city of Lvliang, Shanxi province, as shown in Figure 1(a). The test section of the HFE was constructed over the thick loess foundation in a deep ravine. The geographical location and project profile of the high fill airport are shown in Figure 1(b). For guiding the design and construction of HFE in the loess region, the PCS of the test section, which is filled in the deep ravine [31], was studied in this study.

2.2. Geotechnical Properties of the Foundation Soil. Based on the borehole sampling and laboratory tests [31], the stratum consists of five main types of soils, i.e., $Q_{4}$ loess (3.2-25.8 m), $Q_{3}$ loess (3.1-21.5 m), $Q_{2}$ loess (2.9-14.6 m), silty clay (30.6-48.1 m), and sandy shale $(\geq 12.2 \mathrm{~m})$. The soil used to fill the foundation is mainly composed of $Q_{3}$ loess. The profile of the stratum is shown in Figure 2(a). According to the standard for soil test method (GB/T 50123-2019), soil samples taken from Zone-1, Zone-2, and Zone-3 were used to obtain the physical and mechanical parameters through laboratory tests, including physical index test (water content $w$, dry density $\rho_{\mathrm{d}}$, saturation degree $S_{\mathrm{r}}$, the liquid limit $w_{L}$, and the plastic limit $w_{P}$ ), modified proctor test (the maximum dry density $\rho_{\text {dmax }}$ and the optimal water content $\left.w_{\mathrm{op}}\right)$, oedometer test (the coefficient of compressibility $a_{\mathrm{v}}$ and the compression modulus $E_{\mathrm{s}}$ ), collapsibility coefficient test (the gravity collapsibility coefficient $\delta_{\mathrm{zs}}$ and the collapsibility coefficient $\delta_{s}$ under different vertical stress $\sigma$ ), and direct shear test (the cohesion $c$ and the angle of internal friction $\varphi)$. The variations of the above parameters along the sampling depth are shown in Figures 2(b)-2(j). The statistical mean values of the above parameters of soil samples are listed in Table 2. Note that $a_{\mathrm{v}}$ and $E_{\mathrm{s}}$ are the coefficients of compressibility and compression modulus of undisturbed loess samples when the stress range is between 100 and $200 \mathrm{kPa}$, respectively.

From Figure 2 and Table 2, the water content grows from $8 \%$ to $25 \%$ with depth, and the dry density increases 
TABLE 1: PCS estimation formulas of fill embankment from case studies.

\begin{tabular}{|c|c|c|c|c|c|}
\hline References & \multicolumn{5}{|c|}{ Relationship between crest PCS and fill height of the embankment } \\
\hline \multirow{6}{*}{ [29] } & $\begin{array}{r}\text { Germany and Japan: } S=H^{2} / 3000 \\
\text { Lawton forr }\end{array}$ & $\begin{array}{l}\text { e } S(\mathrm{~m}) \text { is the crest PCS of fill b } \\
=0.001 H^{1.5} \text {, where } S(\mathrm{~m}) \text { is the }\end{array}$ & $\begin{array}{l}H(\mathrm{~m}) \text { is th } \\
\text { PCS of fil }\end{array}$ & ht of fill & nkment \\
\hline & \multirow{4}{*}{ Gu Weici formula: $S_{t}=\mathrm{kH}^{n} e^{-m / t}$} & Empirical coefficient & $k$ & $m$ & $n$ \\
\hline & & Concrete-faced rockfill dam & 0.004331 & 1.746 & 1.2045 \\
\hline & & Earth dam with inclined core & 0.0098 & 1.4755 & 1.0148 \\
\hline & & Core wall dam & 0.016 & 1.0932 & 0.876 \\
\hline & \multicolumn{5}{|c|}{$\begin{array}{c}\text { Russia formula: } S_{t}=-0.453\left(1-e^{0.08 H}\right) e^{0.693 / t^{1.157}} \text {, where } t \text { (days) is the duration of PCS, } S_{t}(\mathrm{~mm}) \text { is the crest PCS of fill } \\
\text { body }\end{array}$} \\
\hline [30] & \multicolumn{5}{|c|}{$\begin{array}{c}\text { Longbao Airport in Guiyang and Dali Airport in Yunnan:S }=H^{2} / \sqrt[3]{E^{2}} \text {, where } E(\mathrm{MPa}) \text { is the deformation modulus of } \\
\text { high fill, where } S(\mathrm{~mm}) \text { is the crest PCS of fill body }\end{array}$} \\
\hline [26] & \multicolumn{5}{|c|}{$S=4.493+\left(0.672 H^{2} / E\right)$, where $S(\mathrm{~mm})$ is the elastic modulus of high fill } \\
\hline [27] & \multicolumn{5}{|c|}{$S=0.0014 H^{0.95}(\lambda \geq 0.85), S=0.7-1.0 \% H$, where $S(\mathrm{~m})$ is the crest PCS of fill body } \\
\hline [28] & \multicolumn{5}{|c|}{$\begin{array}{l}\text { Longdongbao Airport: } S=0.492 H^{1.3823} \text {, where } S(\mathrm{~mm}) \text { is the crest PCS of fill body } \\
\text { Dali Airport: } S=11.6 H-109.8 \text {, where } S(\mathrm{~mm}) \text { is the crest PCS of fill body }\end{array}$} \\
\hline
\end{tabular}

from 1.2 to $1.8 \mathrm{~g} / \mathrm{cm}^{3}$. The results indicate that the natural water content of $Q_{3}$ loess $(w=16.97 \%)$ is higher than the optimal water content $\left(w_{\mathrm{op}}=13.3 \%\right)$. This will have significant consequences on the design since the soil needs to be dried prior to use as a fill material. The mean value of gravity collapsibility coefficient of undisturbed loess is $\delta_{\text {zs }}=0.008$, which is lower than the critical value suggested by the standard for soil test method (GB/T 50123$2019)$, i.e., $\left[\delta_{s}\right]=0.015$. This indicates that the collapsibility of the undisturbed loess can be neglected for the sake of simplicity in engineering design. However, when the stress level $\sigma_{0}>200 \mathrm{kPa}, \delta_{\mathrm{s}} \geq 0.02>\left[\delta_{\mathrm{s}}\right]=0.015$, the collapsibility of foundation loess should be well considered.

\section{Assessment of Foundation Treatment Methods for the Test Section}

3.1. Pile Reinforcement and DC Methods for Foundation Soil. In this study, the DC method and vibrating sinking gravel pile (VSGP) or plain soil compaction pile (PSCP) are adopted to enhance the strength and bearing capacity of the deep loess foundation. The test regions are divided into 10 sections, as shown in Figure 3, with sections A, B, $\mathrm{C}, \mathrm{D}, \mathrm{E}$, and $\mathrm{F}$ reinforced by $\mathrm{DC}$, sections $\mathrm{G}$ and $\mathrm{H}$ by VSGP, and sections $\mathrm{K}$ and $\mathrm{L}$ by PSCP.

The dynamic compactor of W200 A-50t (Hangzhou Heavy Machinery Co., Ltd.) and QUY35 A-35t (FuWa Heavy Industry Machinery Co., Ltd) was employed to reinforce the foundation. The dynamic compact effort (DCE) of the single-point DC is 2000,3000 , and $6000 \mathrm{kN} \cdot \mathrm{m}$ while the DCE of the overlapping DC is 800 and $1000 \mathrm{kN} \cdot \mathrm{m}$, respectively. These single-point DCs are squarely arranged. The tamping distance (TD) is $3.5-5.5 \mathrm{~m}$, and the number of tamping times is 10-12. The stopping standard is defined as the last settlement after tamping less than $3 \mathrm{~cm}$. The number of tamping times of the overlapping DC is $3-6$, and the length of overlapping is TD/4. The stopping standard is defined as the last settlement after tamping less than $5 \mathrm{~cm}$. The design of the DC reinforcement test is illustrated in Figure 4 and Table 3.
3.2. Combined Compaction Methods for HFE. The HFE is intended to be constructed by the following four methods:

(1) Vibration compaction method (VC): the $50 t$ vibration compactor is used with the walking speed $\leq 3 \mathrm{~km} / \mathrm{h}$ and the times of rolling $=4,6,8$, and 10 . The thickness of the loose laying soil (TLLS) is controlled to be $0.4 \mathrm{~m}, 0.5 \mathrm{~m}$, and $0.6 \mathrm{~m}$, respectively

(2) Percussive compaction method (PC): the triangular compactor $\left(25 \mathrm{~T}_{3}-25 \mathrm{~kJ}\right)$ is adopted here, with the walking speed $\geq 10 \mathrm{~km} / \mathrm{h}$, and the times of rolling $=10,15,20$, and 25 . The TLLS is controlled to be $0.7 \mathrm{~m}, 0.8 \mathrm{~m}$, and $0.9 \mathrm{~m}$, respectively

(3) VC + PC method: in the first step, the VC method is used to reach a fill thickness of $1.5 \mathrm{~m}$ (times of rolling $=10$, TLLS $=0.4 \mathrm{~m}, \lambda=0.93$ ). Here, $\lambda$ denotes the compaction degree of the fill. The PC method is adopted in the second step with the times of rolling $=10,15,20$, and 25

(4) VC + DC method: first, the thickness of the fill reaches $6.0 \mathrm{~m}$ using the $\mathrm{VC}$ method (times of rolling $=10$, TLLS $=0.4 \mathrm{~m}, \lambda=0.93)$. Next, the singlepoint DC (tamping times $=8-10$ ) with the DCE of $2000-3000 \mathrm{kN} \cdot \mathrm{m}$ and an overlapping DC (tamping times $=3-5)$ with the DCE of $1000 \mathrm{kN} \cdot \mathrm{m}$ are employed to further reinforce the fill embankment

3.3. Evaluation of Reinforcement Effect of the Foundation before and after DC. In order to comprehensively evaluate the reinforcement effects of the foundation before and after DC, the oedometer tests, direct shear tests, and plate load tests of the undisturbed loess (before DC) and the compacted loess (after DC) are carried out. The plate load test results are shown in Table 4 . The mechanical parameters of the undisturbed soil (before DC) and compacted soil (after DC) at different depths are shown in Table 5.

From Tables 4 and 5, during the DC stage with the DCE of 2000,3000 , and $6000 \mathrm{kN} \cdot \mathrm{m}$, the optimal tamping times are 11,11 , and 10 , respectively, while the effective reinforcement depths of the fill are $5.0 \mathrm{~m}, 6.0 \mathrm{~m}$, and $9.0 \mathrm{~m}$. In the range of 


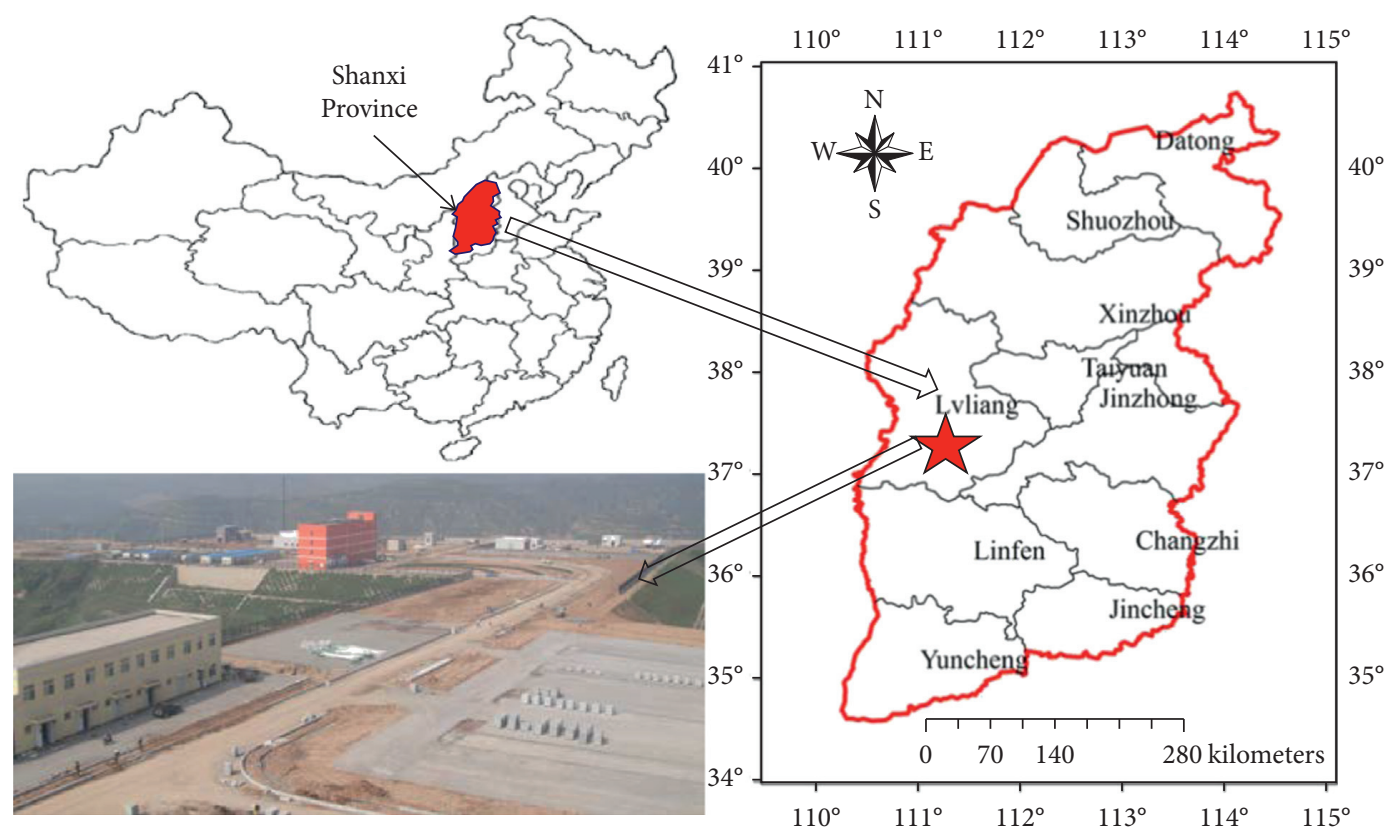

(a)

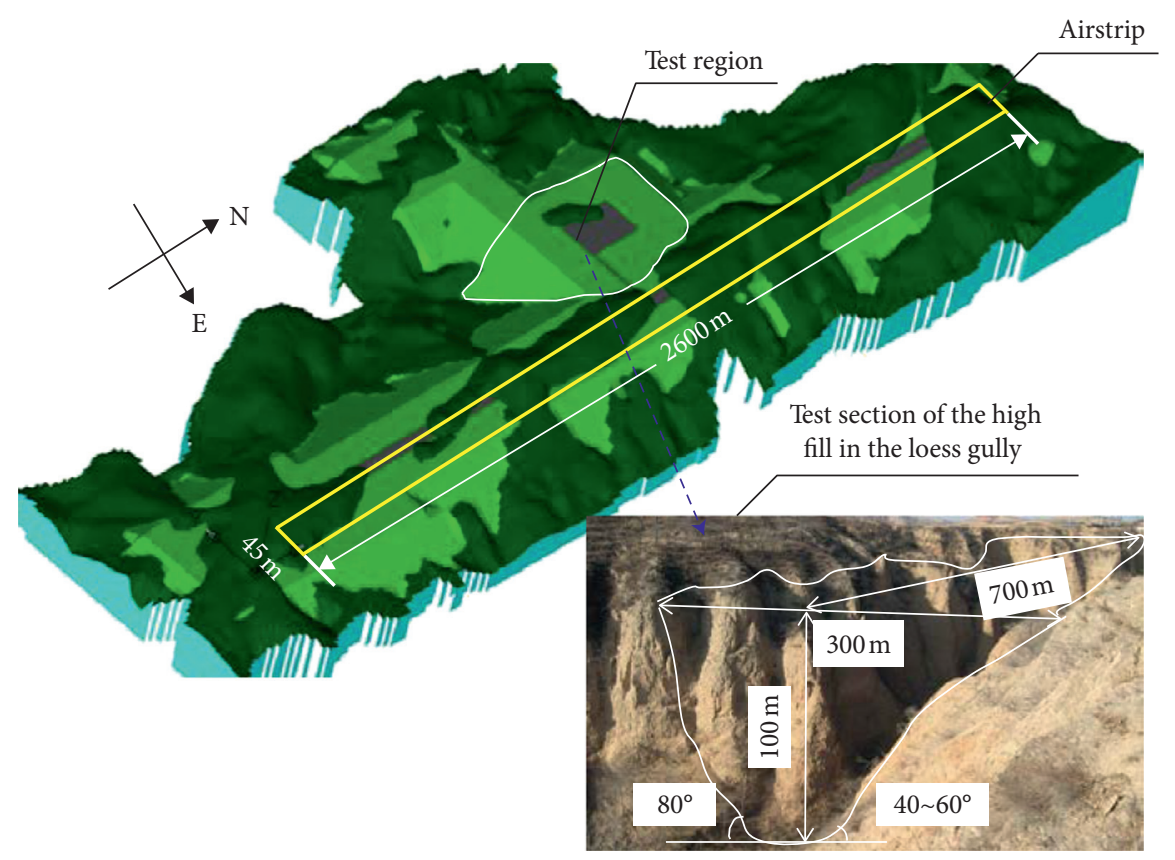

High fill

Excavation

Bed rock

(b)

Figure 1: Overview of Lvliang Airport. (a) Geographical location of Lvliang Airport. (b) Profile of the high fill of Lvliang Airport (after [31]).

the reinforcement depth, the bearing capacity of the compacted soil after DC is $P=300-400 \mathrm{kPa}$. Besides, the compression modulus of the compacted soil after DC is 1.6-3.8 times that of the undisturbed soil. The cohesion is 2.9-5.5 times that of the undisturbed soil while the internal friction angle exhibits little change. Through the load plate test, the deformation modulus of the foundation after DC is 28.0-35.0 MPa, with an average value of about $30.6 \mathrm{MPa}$. After DC, the collapsibility coefficient of the loess decreases while the compression modulus and shear strength increase. However, the effective reinforcement depth is limited. The total reinforcement effect of the foundation with the DC 

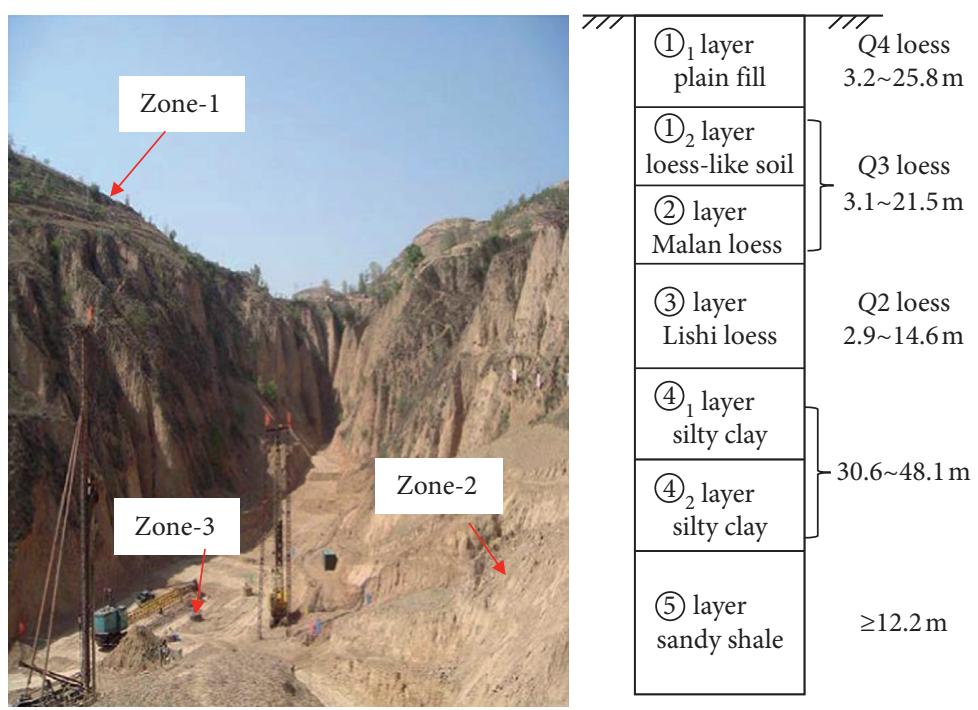

(a)

$\rho_{\mathrm{d}}\left(\mathrm{g} / \mathrm{cm}^{3}\right)$

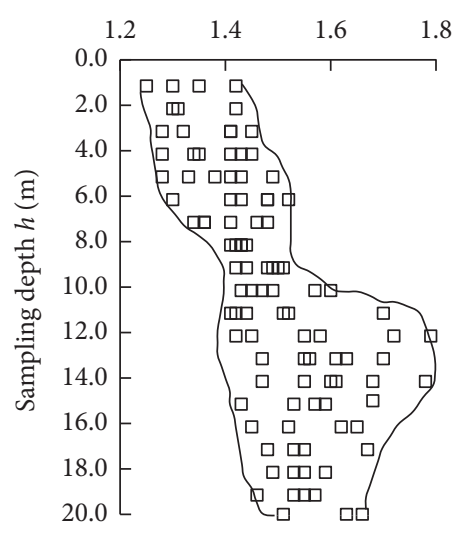

(c)

$$
w_{1}(\%)
$$

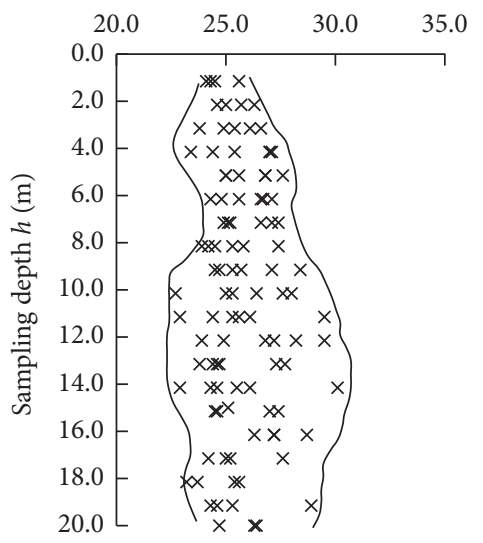

(e)

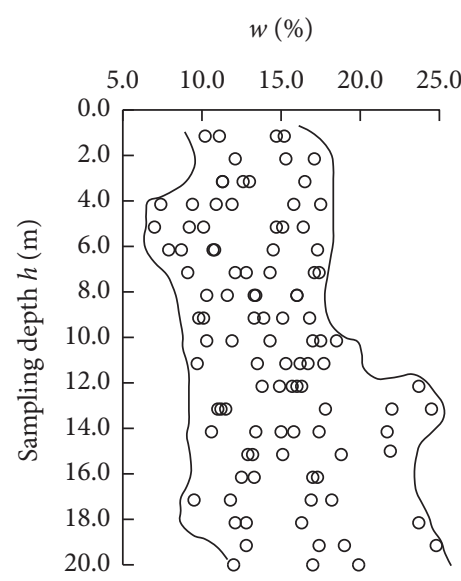

(b)

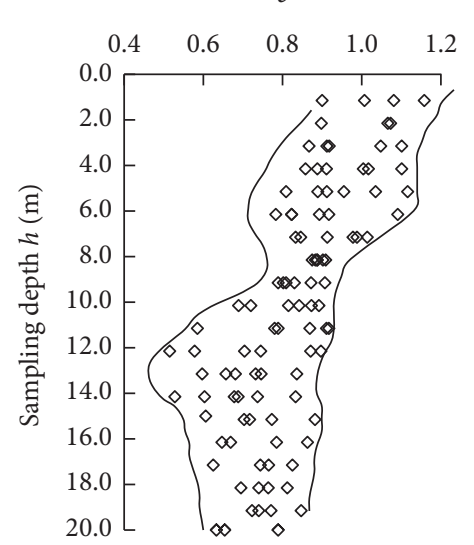

(d)

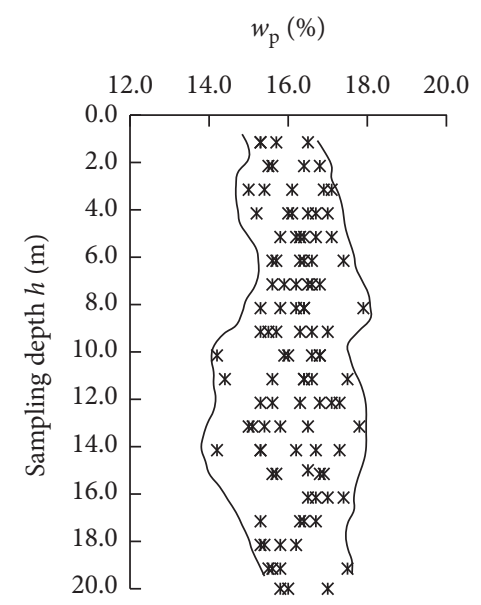

(f)

Figure 2: Continued. 


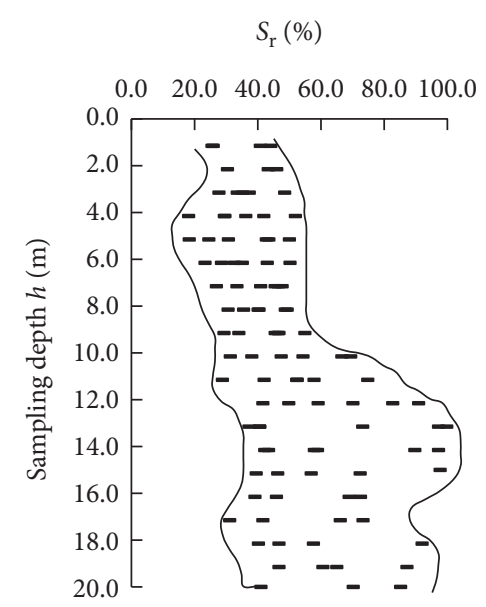

(g)

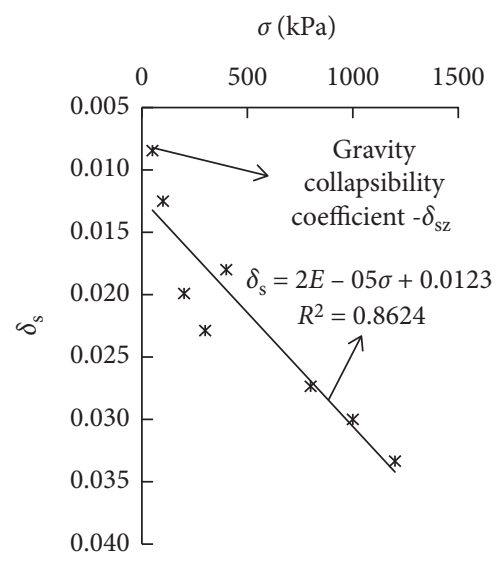

(i)

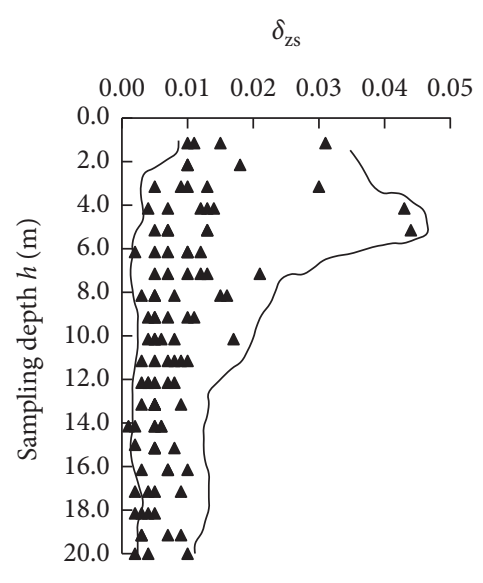

(h)

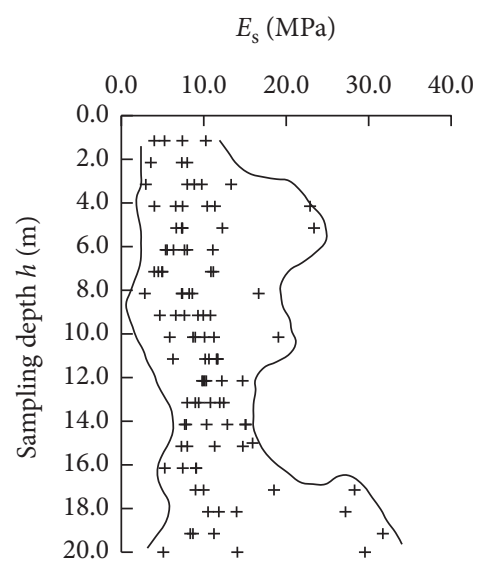

(j)

Figure 2: Profile of the stratum of the test section and physical-mechanical parameters of soil samples. (a) Profile of the stratum of the test section of the airport. (b) Water content. (c) Dry density. (d) Void ratio. (e) Liquid limit. (f) Plastic limit. (g) Saturation degree. (h) Gravity collapsibility coefficient. (i) Collapsibility coefficient. (j) Compression modulus.

TABLE 2: Mean values of physical and mechanical parameters of soil samples.

\begin{tabular}{lccccccccccc}
\hline Layer & $w(\%)$ & $\rho_{\mathrm{d}}\left(\mathrm{g} / \mathrm{cm}^{3}\right)$ & $\rho_{\mathrm{d} \max }\left(\mathrm{g} / \mathrm{cm}^{3}\right)$ & $w_{\mathrm{op}}(\%)$ & $e$ & $w_{L}(\%)$ & $w_{P}(\%)$ & $a_{\mathrm{v}}\left(\mathrm{MPa}^{-1}\right)$ & $E_{\mathrm{s}}(\mathrm{MPa})$ & $c(\mathrm{kPa})$ & $\varphi\left({ }^{\circ}\right)$ \\
\hline (1) $_{1}$ & 23.66 & 1.60 & - & - & 0.696 & 25.20 & 15.89 & 0.396 & 4.65 & 19.3 & 20.5 \\
(1) $_{2}$ & 15.65 & 1.44 & - & - & 0.882 & 24.72 & 15.75 & 0.249 & 7.48 & 49.4 & 26.6 \\
(2) $^{2}$ & 16.97 & 1.56 & 1.88 & 13.3 & 0.741 & 24.87 & 16.08 & 0.228 & 8.23 & 36.6 & 23.6 \\
(3) & 21.36 & 1.65 & 1.93 & 12.2 & 0.647 & 29.29 & 17.49 & 0.231 & 7.57 & 70.2 & 23.5 \\
(4) $_{1}$ & 22.00 & 1.64 & - & - & 0.663 & 29.91 & 17.53 & 0.238 & 7.20 & 114.9 & 21.3 \\
(4) $_{2}$ & 21.53 & 1.67 & - & - & 0.628 & 30.13 & 17.66 & 0.229 & 7.21 & 126.6 & 22.8 \\
\hline
\end{tabular}

method is affected by not only the DCE but also the thickness and soil property. Moreover, the bearing capacities of the foundations treated by the VSGP and PSCP methods are $400 \mathrm{kPa}$ and $340 \mathrm{kPa}$, respectively. The deformation moduli of the soil after VSGP and PSCP reinforcement are 2.3 and 2.0 times those of the undisturbed soil, respectively. It shows that the treatment of the foundation by the VSGP or PSCP method can also reinforce the original loess foundation. However, the borehole can easily collapse during the piling process when the water content of the foundation is too high. Therefore, the above methods are well suited for treating the loess foundation with low water content. Hence, soil improvement methods using admixtures like stone, cement, lime, fly ash, or mixed columns should be used in this case, e.g., the CFG piles.

3.4. Reinforcement Effect on the Fill Body. In order to determine the reinforcement effect on the fill body after different reinforcement methods, the compaction degree tests, shallow plate load tests, oedometer tests, and direct shear tests are carried out. The plate load test results of 


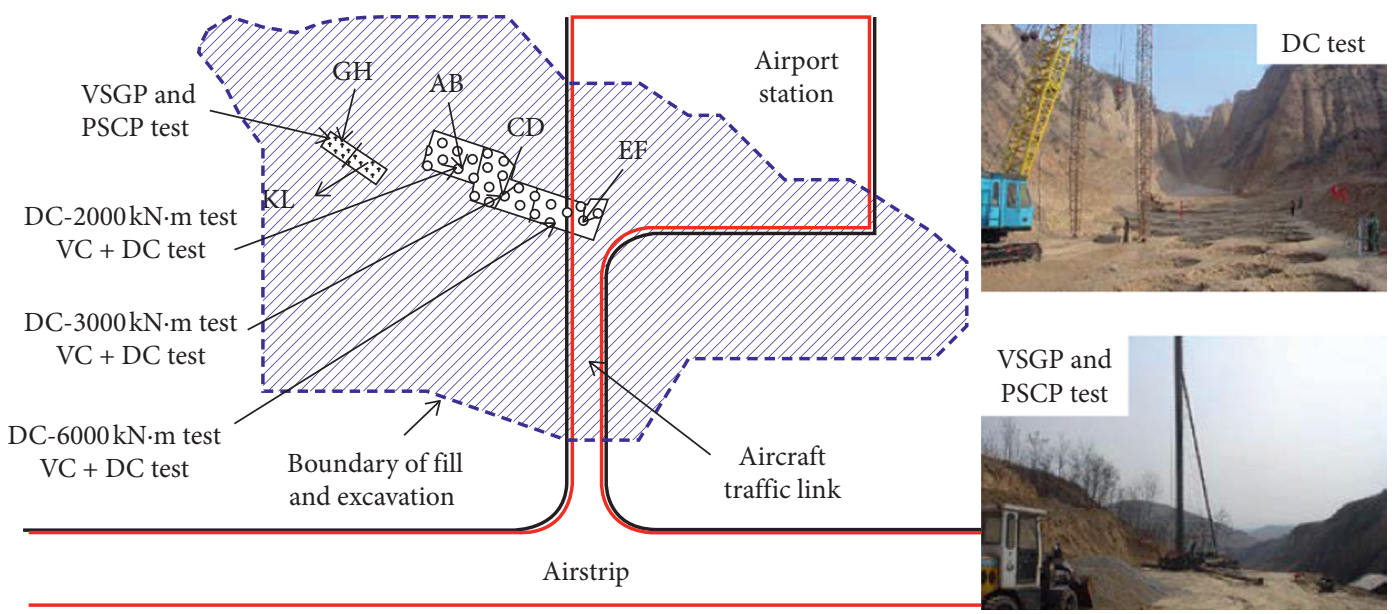

Figure 3: Reinforcement methods for the deep loess foundation.

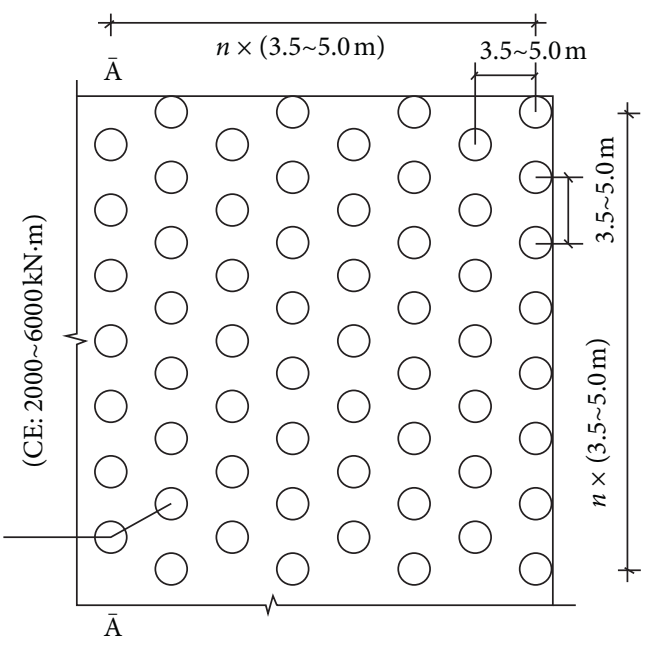

(a)

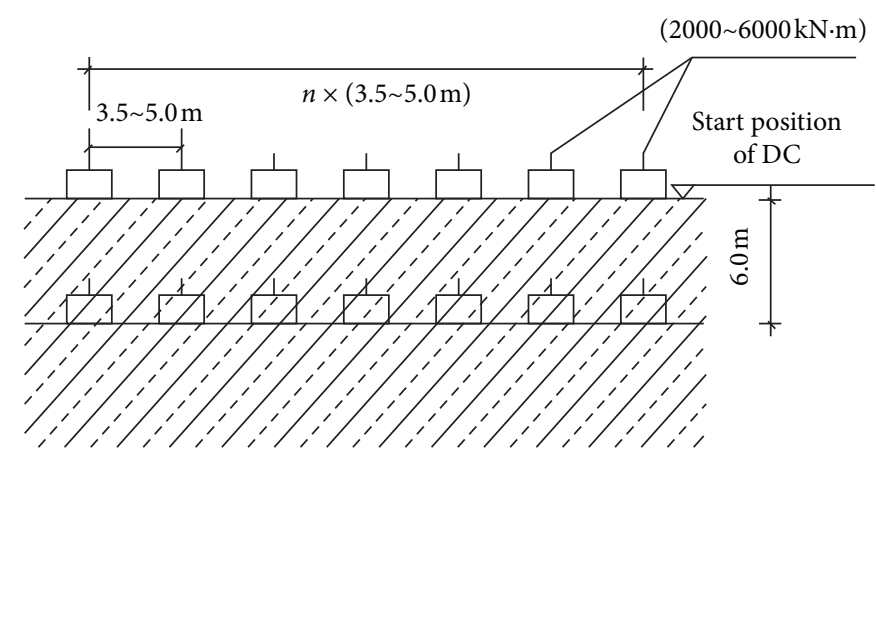

(b)

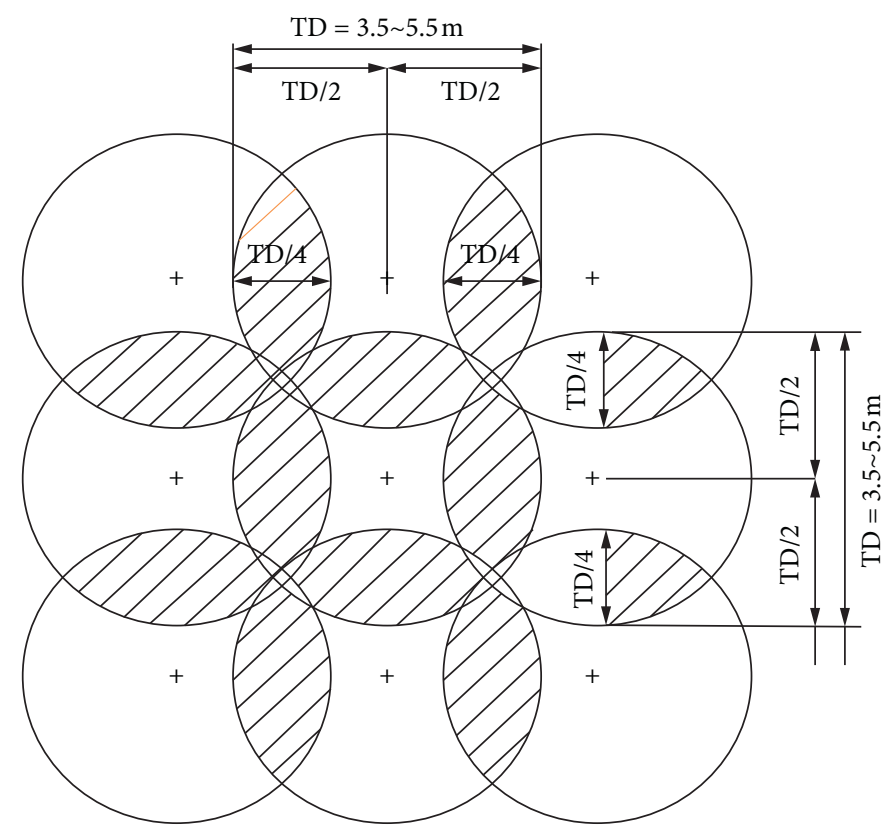

(c)

Figure 4: Design scheme for DCs. (a) Plane layout of DCs. (b) A-A section. (c) Overlapping design of overlapping DCs. 
TABLE 3: Foundation soil treatment methods.

\begin{tabular}{|c|c|c|c|c|}
\hline Section & & Areas $\left(\mathrm{m}^{2}\right)$ & Treatment methods & Abbreviations or symbols \\
\hline \multirow{6}{*}{ DC } & A & $20 \mathrm{~m} \times 20 \mathrm{~m}$ & $\begin{array}{c}\text { Single-point } \mathrm{DC}-2000 \mathrm{kN} \cdot \mathrm{m}(\mathrm{TT}=10-12), \mathrm{TD}=3.5 \mathrm{~m} ; \mathrm{TD} / 4 \text {-overlapping } \\
\mathrm{DC}-800 \mathrm{kN} \cdot \mathrm{m}(\mathrm{TT}=3-5)\end{array}$ & DC-dynamic compaction \\
\hline & $\mathrm{B}$ & $20 \mathrm{~m} \times 20 \mathrm{~m}$ & $\begin{array}{l}\text { Single-point DC-2000 kN.m }(\mathrm{TT}=10-12), \mathrm{TD}=4.0 \mathrm{~m} \text {; TD/4-overlapping DC- } \\
\qquad 800 \mathrm{kN} \cdot \mathrm{m}(\mathrm{TT}=3-5)\end{array}$ & $\begin{array}{l}\text { VSGP-vibrating sinking } \\
\text { gravel pile }\end{array}$ \\
\hline & $\mathrm{C}$ & $20 \mathrm{~m} \times 20 \mathrm{~m}$ & $\begin{array}{c}\text { Single-point DC-3000 kN } \cdot \mathrm{m}(\mathrm{TT}=10-12), \mathrm{TD}=4.0 \mathrm{~m} ; \mathrm{TD} / 4 \text {-overlapping DC- } \\
1000 \mathrm{kN} \cdot \mathrm{m}(\mathrm{TT}=3-5)\end{array}$ & $\begin{array}{l}\text { PSCP-plain soil compaction } \\
\text { pile }\end{array}$ \\
\hline & $\mathrm{D}$ & $20 \mathrm{~m} \times 20 \mathrm{~m}$ & $\begin{array}{l}\text { Single-point DC-3000 kN.m }(\mathrm{TT}=10-12), \mathrm{TD}=4.5 \mathrm{~m} ; \mathrm{TD} / 4 \text {-overlapping DC- } \\
1000 \mathrm{kN} \cdot \mathrm{m}(\mathrm{TT}=3-5)\end{array}$ & TD-tamping distance \\
\hline & $\mathrm{E}$ & $20 \mathrm{~m} \times 20 \mathrm{~m}$ & $\begin{array}{l}\text { Single-point DC- } 6000 \mathrm{kN} \cdot \mathrm{m}(\mathrm{TT}=10-12), \mathrm{TD}=4.5 \mathrm{~m} \text {; TD/4-overlapping DC- } \\
1000 \mathrm{kN} \cdot \mathrm{m}(\mathrm{TT}=4-6)\end{array}$ & TT-tamping times \\
\hline & $\mathrm{F}$ & $20 \mathrm{~m} \times 20 \mathrm{~m}$ & $\begin{array}{l}\text { Single-point DC-6000 kN.m }(\mathrm{TT}=10-12), \mathrm{TD}=5.0 \mathrm{~m} ; \mathrm{TD} / 4 \text {-overlapping DC- } \\
1000 \mathrm{kN} \cdot \mathrm{m}(\mathrm{TT}=4-6)\end{array}$ & \\
\hline \multirow{2}{*}{ VSGP } & G & $20 \mathrm{~m} \times 15 \mathrm{~m}$ & $d=0.5 \mathrm{~m}, l=1.5 \mathrm{~m}, L=10-18 \mathrm{~m}($ average value $=15 \mathrm{~m})$ & $d$-pile dia \\
\hline & $\mathrm{H}$ & $20 \mathrm{~m} \times 15 \mathrm{~m}$ & $d=0.5 \mathrm{~m}, l=2.0 \mathrm{~m}, L=10-18 \mathrm{~m}($ average value $=15 \mathrm{~m})$ & l-pile spacing; L-pile spacing \\
\hline \multirow{2}{*}{ PSCP } & K & $20 \mathrm{~m} \times 15 \mathrm{~m}$ & $d=0.5 \mathrm{~m}, l=1.5 \mathrm{~m}, L=10-18 \mathrm{~m}($ average value $=15 \mathrm{~m})$ & \\
\hline & $\mathrm{L}$ & $20 \mathrm{~m} \times 15 \mathrm{~m}$ & $d=0.5 \mathrm{~m}, l=2.0 \mathrm{~m}, L=10-18 \mathrm{~m}($ average value $=15 \mathrm{~m})$ & \\
\hline
\end{tabular}

TABLE 4: Plate load test results of loess before and after DC with different reinforcement methods.

\begin{tabular}{ccccccccc}
\hline \multicolumn{2}{c}{ Types of loess } & $I_{0}$ & $\mu$ & $d_{0}(\mathrm{~m})$ & $\gamma\left(\mathrm{kN} / \mathrm{m}^{3}\right)$ & $P(\mathrm{kPa})$ & $s(\mathrm{~mm})$ & $E_{0}(\mathrm{MPa})$ \\
\hline \multirow{4}{*}{ Undisturbed loess } & $Q_{2}$ & 0.785 & 0.38 & 0.6 & 20.0 & $360-450$ & $5.8-7.7$ & 23.5 \\
& $Q_{3}($ Zone-1) & 0.785 & 0.35 & 0.8 & 18.5 & 87.5 & $11.8-13.2$ & 3.9 \\
& $Q_{3}$ (Zone-3) & 0.785 & 0.35 & 0.8 & 18.8 & $120-135$ & $10.7-11.5$ & 6.5 \\
\hline \multirow{6}{*}{ Compacted loess } & DC (2000 kN.m) & 0.886 & 0.35 & 1.0 & 21.0 & $310-420$ & $6.32-9.96$ & 30.0 \\
& DC (3000 kN.m) & 0.886 & 0.35 & 1.0 & 21.0 & $320-450$ & $8.97-10.0$ & 35.0 \\
& DC (6000 kN.m) & 0.886 & 0.35 & 1.0 & 21.0 & $360-420$ & $6.78-8.36$ & 39.0 \\
& VC + DC (2000 kN.m) & 0.886 & 0.35 & 1.0 & 21.0 & $350-360$ & $9.69-10.0$ & 28.0 \\
& VC + DC (3000 kN.m) & 0.886 & 0.35 & 1.0 & 21.0 & $360-400$ & $9.45-10.0$ & 28.8 \\
& VSGP & 0.785 & 0.35 & 0.5 & 23.0 & $336-500$ & $9.2-10.0$ & 13.2 \\
& PSCP & 0.785 & 0.27 & 0.5 & 21.0 & $240-410$ & $10.0-15.0$ & 16.0 \\
\hline
\end{tabular}

Note. $I_{0}$ is the shape factor of the rigid bearing plate; $\mu$ is Poisson's ratio of soil; $d_{0}$ is the diameter or edge length of the rigid bearing plate; $\gamma$ is the unit weight of soil; $s$ is the settlement of the rigid bearing plate; $P$ is the bearing capacity value; $E_{0}$ is the deformation modulus.

TABLE 5: Laboratory test results of mechanical parameters of the soil before and after DC.

\begin{tabular}{|c|c|c|c|c|c|c|c|c|}
\hline \multirow{2}{*}{ Depth/(m) } & \multicolumn{2}{|c|}{$E_{\mathrm{s}}(\mathrm{MPa})$} & \multicolumn{2}{|c|}{$\mathrm{c}(\mathrm{kPa})$} & \multicolumn{2}{|c|}{$\varphi\left({ }^{\circ}\right)$} & \multicolumn{2}{|c|}{$\delta_{\mathrm{s}}$} \\
\hline & Before DC & After DC & Before DC & After DC & Before DC & After DC & Before DC & After DC \\
\hline 1 & 5.4 & 20.6 & 18.0 & - & 19.1 & - & 0.093 & 0.016 \\
\hline 2 & 4.9 & 15.8 & 24.5 & - & 18.5 & - & 0.080 & 0.015 \\
\hline 3 & 5.7 & 17.0 & 26.5 & 76.9 & 25.0 & 27.1 & 0.078 & 0.015 \\
\hline 4 & 5.5 & 18.2 & 33.0 & - & 19.8 & - & 0.073 & 0.014 \\
\hline 5 & 7.2 & 14.3 & 22.0 & 56.3 & 23.1 & 27.9 & 0.057 & 0.013 \\
\hline 6 & 7.1 & 11.4 & 21.0 & 115.0 & 23.6 & 13.6 & 0.055 & 0.013 \\
\hline 7 & 7.1 & 12.4 & 31.3 & - & 20.7 & - & 0.054 & 0.012 \\
\hline 8 & 7.9 & 15.2 & 33.0 & - & 20.8 & - & 0.050 & 0.010 \\
\hline 9 & 6.1 & 18.2 & 23.0 & 117.0 & 22.7 & 22.3 & 0.025 & 0.009 \\
\hline 10 & 7.8 & 17.7 & 36.5 & - & 20.6 & - & 0.020 & 0.008 \\
\hline
\end{tabular}

$\mathrm{VC}+2000 \mathrm{kN} \cdot \mathrm{m}-\mathrm{DC}$ and $\mathrm{VC}+3000 \mathrm{kN} \cdot \mathrm{m}-\mathrm{DC}$ are shown in Table 4. The compaction degree of soil after reinforcement and three characteristic mechanical parameters (i.e., compression modulus, cohesion, and internal friction angle) are shown in Figures 5-7.

When the VC method is used for reinforcing the fill embankment, the smaller the thickness of the loose laying soil (TLLS) and the greater the number of tamping times (TT) of compaction, the more obvious the compaction effect. The average compaction degree $\lambda \leq 0.90$ when the TLLS $=0.4-0.6 \mathrm{~m}$ and the TT is $4-6$, while $\lambda \geq 0.93$ when the TT of the VC is $8-10$. It is recommended that the TLLS is $0.4 \mathrm{~m}$ and the TT for the VC method is 10 . When the PC method is used for reinforcing the fill embankment and the TLLS $=0.7-0.8 \mathrm{~m}$, the average compaction degree $\lambda=0.90$, $0.93,0.95$, and 0.98 when $\mathrm{TT}=10,15,20$, and 25 , respectively. When the VC + PC method is used, the first step is to compact 4 layers (the thickness of each layer is $0.4 \mathrm{~m}$ ) of 


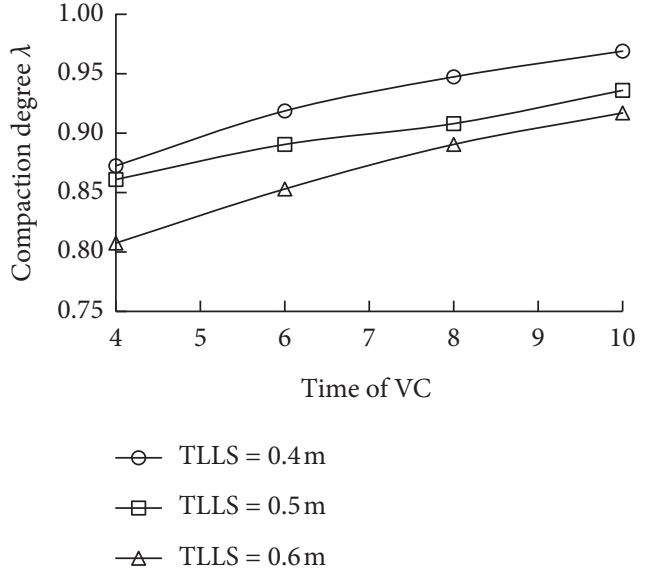

(a)

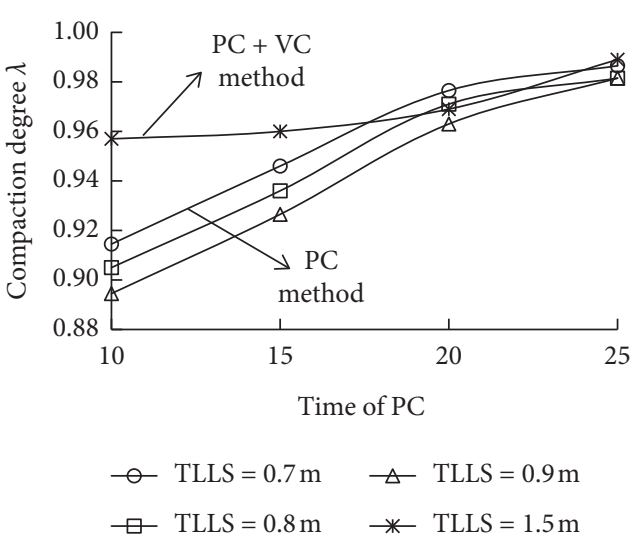

(b)

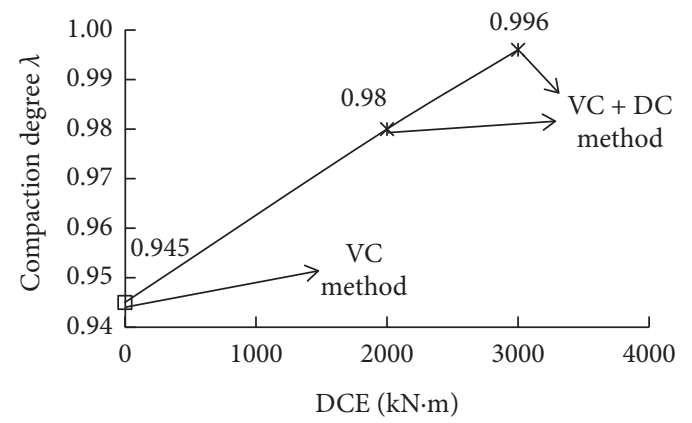

(c)

Figure 5: Compaction degree with different reinforcement methods. (a) VC method. (b) VC or VC + PC method. (c) VC or VC + DC method.

loose soil to reach $1.5 \mathrm{~m}$. Secondly, the PC method is used to further reinforce the fill. When the TT of the PC method is 15,20 , and 25 , the corresponding compaction degree is 0.95 , 0.96 , and 0.98 , respectively. When the VC+DC method is used, the VC method is first utilized. An average compaction degree that exceeds 0.945 is achieved when $\mathrm{TT}=10$. When the thickness of the fill reaches $6.0 \mathrm{~m}$, the DC method with the DCE of 2000 or $3000 \mathrm{kN} \cdot \mathrm{m}$ can be used to further reinforce the fill, and the compaction degree can increase to 0.98 and 0.996 , respectively. The bearing capacity of the fill embankment can reach $350 \mathrm{kPa}$.

At the optimal water content, the deformation modulus of the fill foundation is about $E_{0}=28.5 \mathrm{MPa}$ after reinforcement by the VC + DC method, which is 4.4 times that of the foundation soil. At higher water contents, the compression modulus $\left(E_{\mathrm{s}}\right)$ and the shear strength index $(c, \varphi)$ of the $Q_{2}$ and $Q_{3}$ loess quickly decrease. The compression modulus $E_{\mathrm{s}}$ increases linearly with the axial stress $\sigma$; the higher the compaction, the larger the $E_{\mathrm{s}}, c$, and $\varphi$. When the compaction degree is enhanced by $3 \%$, the compression modulus increases by $15 \%$, while the cohesion and internal friction angle increase by $21 \%$ and $4 \%$, respectively. When the water content increases by $20 \%$, the cohesion and internal friction angle decrease by $14 \%$ and $5 \%$, respectively. With the increase of the compaction degree and the water content of the soil is close to the optimal value, the compressive properties and strength characteristics of the soil can be significantly improved, which is of great significance for the PCS and the stability of the HFE.

\subsection{Adopted Reinforcement Methods of the HFE}

3.5.1. DC Methods of the Foundation Soil. Based on the collapsibility level and the thickness of the loess, the foundation is divided into six zones, which are Zone D1 (4-6 m, alluvial soil), Zone D2-1 (4-6 m, alluvial soil), Zone D2-2 (the bottom of the slope), Zone D3 (less than $7 \mathrm{~m}$, loess with slight collapsibility, $\left.0.016 \leq \delta_{s} \leq 0.029\right)$, Zone D4 (7$10 \mathrm{~m}$, loess with medium collapsibility, $0.031 \leq \delta_{s} \leq 0.065$ ), and Zone D5 ( $>10 \mathrm{~m}$, loess with strong collapsibility, $\left.0.071 \leq \delta_{s} \leq 0.093\right)$, as shown in Figure 8 .

The foundation soil is firstly tamped with the singlepoint DC method, followed by the overlapping DC method. For Zones D1, D2-1, D3, and D2-2, the single-point DC $(\mathrm{DCE}=3000 \mathrm{kN} \cdot \mathrm{m}, \quad \mathrm{TD}=3.5-4.0 \mathrm{~m}, \quad \mathrm{TT}=10-12) \quad$ and overlapping $\mathrm{DC} \quad(\mathrm{DCE}=1000 \mathrm{kN} \cdot \mathrm{m}$, overlapping distance $=1.0 \mathrm{~m}, \mathrm{TT}=3-4)$ are utilized in the foundation soil treatment. For Zone D4, the single-point DC $(\mathrm{DCE}=6000 \mathrm{kN} \cdot \mathrm{m}, \mathrm{TD}=5.0 \mathrm{~m}, \mathrm{TT}=10-12)$ and overlapping $\mathrm{DC} \quad(\mathrm{DCE}=1000 \mathrm{kN} \cdot \mathrm{m}, \quad$ overlapping distance $=1.25 \mathrm{~m}$, TT $=4-5$ ) are utilized. For Zone D5, the 

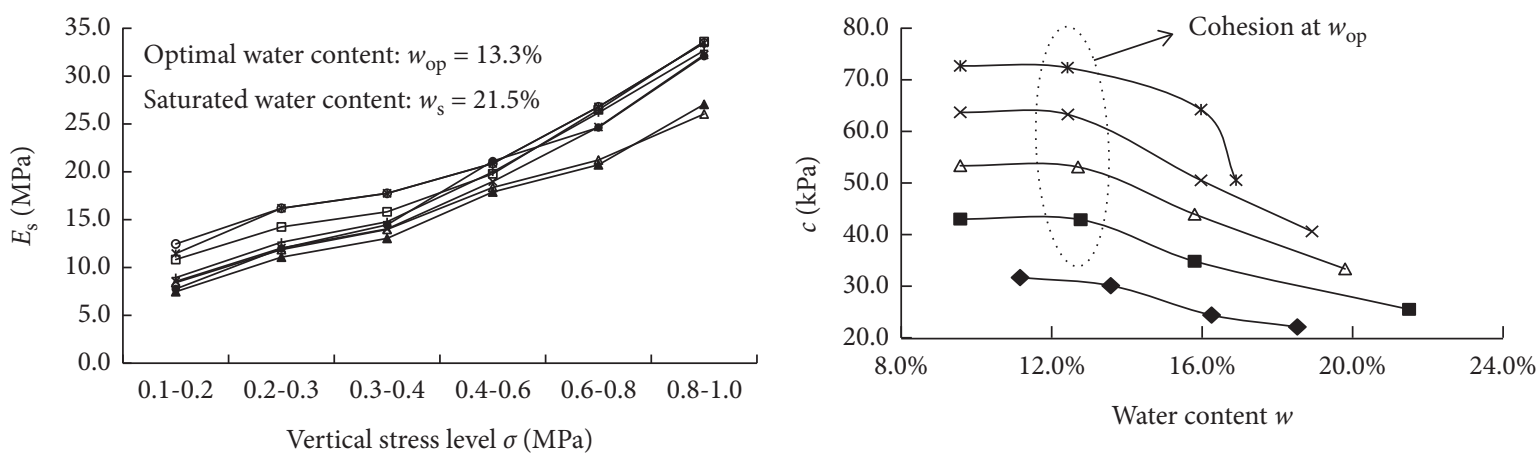

$$
\begin{aligned}
& \triangle \lambda=0.90, w=13.3 \% \quad \rightarrow \quad \lambda=0.93, w=13.3 \% \\
& \neg \lambda=0.96, w=13.3 \% \quad \rightarrow \lambda=0.98, w=13.3 \% \\
& \rightarrow \lambda=0.90, w=21.5 \% \quad \rightarrow \lambda=0.93, w=21.5 \% \\
& \longrightarrow \lambda=0.96, w=21.5 \% \quad * \lambda=0.98, w=21.5 \%
\end{aligned}
$$

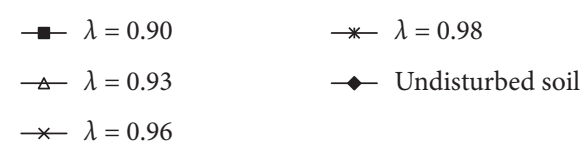

(a)

(b)

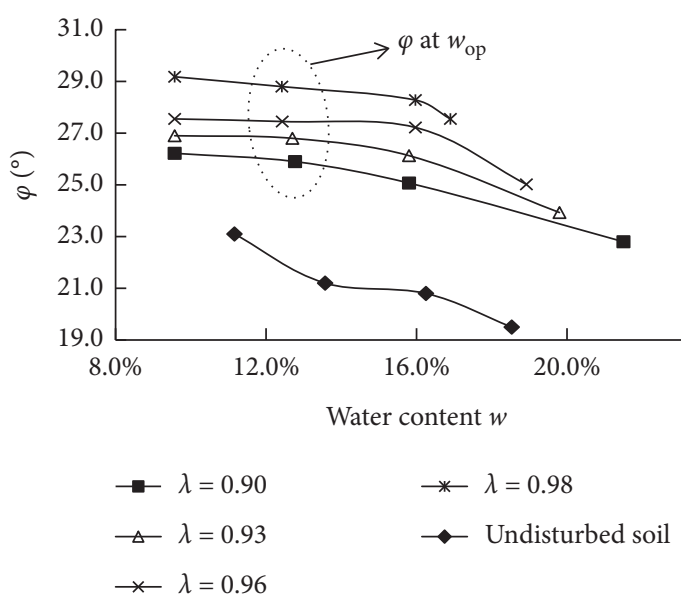

(c)

Figure 6: Mechanical parameters of compacted $Q_{3}$ loess. (a) Compression modulus of soil samples at various stress levels. (b) The cohesion of soil samples at various compaction degrees and water contents. (c) Internal friction angle of soil samples at various compaction degrees and water contents.

single-point $\quad \mathrm{DC} \quad(\mathrm{DCE}=10000 \mathrm{kN} \cdot \mathrm{m}, \quad \mathrm{TD}=5.5 \mathrm{~m}$, $\mathrm{TT}=10-12)$ and overlapping $\mathrm{DC} \quad(\mathrm{DCE}=1500 \mathrm{kN} \cdot \mathrm{m}$, overlapping distance $=1.375 \mathrm{~m}, \mathrm{TT}=4-6$ ) are utilized.

3.5.2. Combined Reinforcement Methods of the Fill Body. The high fill in the test section is compacted with loose $Q_{3}$, $Q_{2}$ loess, which is divided into three domains, i.e., the fill slope zone, the ordinary zone, and the airstrip zone. Combined reinforcement methods including the VC, PC, and DC methods are used. The compaction methods of high fill are shown in Figure 9 and Table 6. For the airstrip zone, the $20 \mathrm{~m}$ thick of loess is compacted with $\mathrm{VC}+\mathrm{PC}$ and $\mathrm{VC}+\mathrm{DC}$ methods. The loose layer of soils with the $\mathrm{VC}$ method is $0.35-0.50 \mathrm{~m}$ while $1.0-1.5 \mathrm{~m}$ for the PC method. The compaction degree is designed between 0.96 and 0.98 . The single-point $\mathrm{DC}(\mathrm{DCE}=3000 \mathrm{kN} \cdot \mathrm{m})$ is used to reinforce the fill body when the fill thickness reaches $6 \mathrm{~m}$. The compaction degrees in other regions are controlled between 0.90 and 0.93 .

\section{PCS Prediction of the HFE}

4.1. In Situ Monitoring System of PCS. The maximum fill height of the test section in Lvliang Airport is $80.0 \mathrm{~m}$, and the digital electronic level and deep-layer settlement gauges are used for monitoring the PCS of the fill body and the foundation soil. The deep-layer settlement gauges (CX-1, CX-2, CX-3, and CX-4) are installed in the high fill slope region, as shown in Figure 9. The surface monitoring points of the HFE during the intermission period and the postconstruction period are shown in Figures 10(a) and 10(b). During the construction stage, the in situ monitoring data are recorded every day. During the postconstruction stage, the measured data are registered once every 10 days for three months, followed by once every 30 days after that. The 

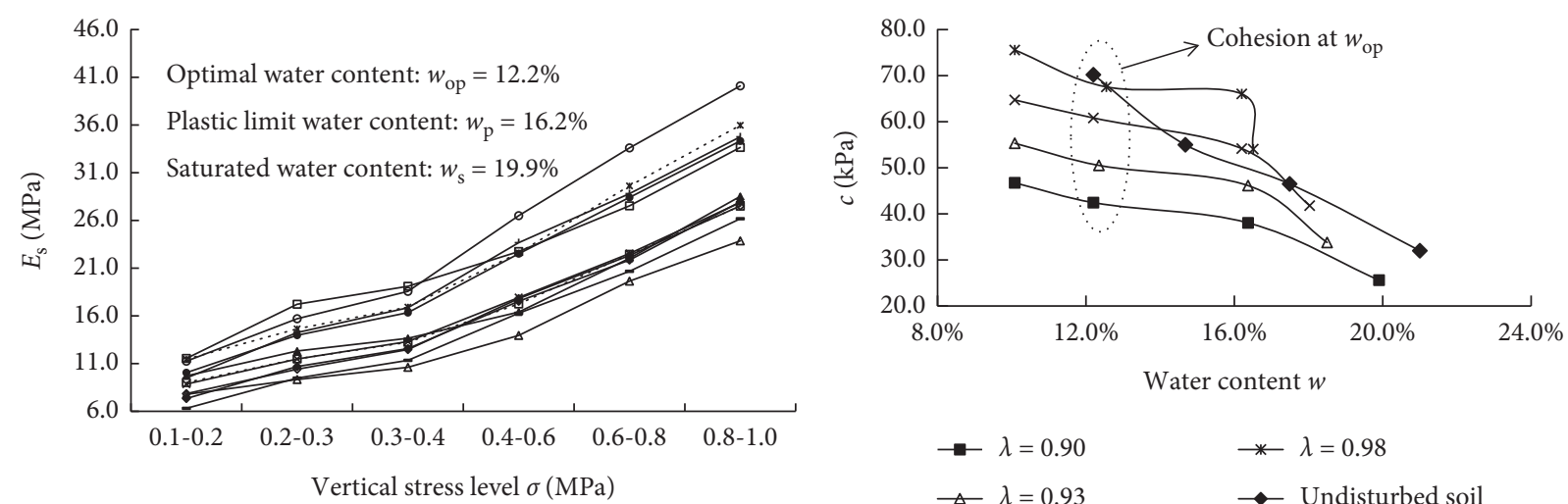

$$
\begin{aligned}
& \triangle \lambda=0.90, w=12.2 \% \quad \ldots * \cdot \lambda=0.98, w=16.2 \% \\
& \rightarrow \lambda=0.98, w=12.2 \% \quad \text {. } \square \text {. } \lambda=0.96, w=19.9 \% \\
& \rightarrow \lambda=0.96, w=16.2 \% \quad \rightarrow \lambda=0.96, w=12.2 \% \\
& \longrightarrow \lambda=0.93, w=19.9 \% \quad \longrightarrow \lambda=0.93, w=16.2 \% \\
& \rightarrow \lambda=0.93, w=12.2 \% \quad \longrightarrow \lambda=0.90, w=19.9 \% \\
& \rightarrow \lambda=0.90, w=16.2 \% \quad \rightarrow \lambda=0.98, w=19.9 \%
\end{aligned}
$$

(a)

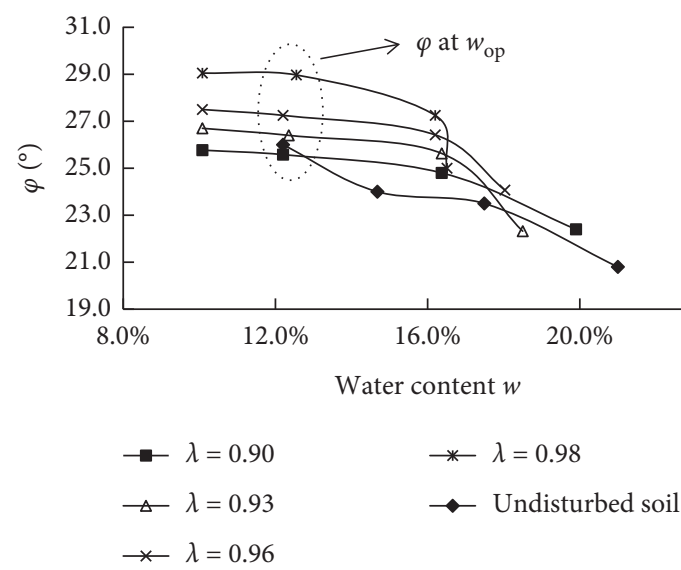

(c)

Figure 7: Mechanical parameters of compacted $Q_{2}$ loess. (a) Compression modulus at various compaction degrees and water contents. (b) Cohesion at various compaction degrees and water contents. (c) Internal friction angle at various compaction degrees and water contents.

benchmarks from BM-1 to BM-7 are installed in the stable loess ridge and proofread one time every three months, as shown in Figure 10(c). The monitoring duration for the intermission stage consists of 113 days in winter and 342 days in the postconstruction stage.

4.2. Components of PCS of the HFE. In order to analyze the long-term PCS for assessing the engineering stability, it is necessary to divide the total PCS into two parts, i.e., the fill body and the foundation. According to the in situ monitoring data of the deep-layered settlement gauges, the PCS of the foundation is $S_{o}$. The layer settlements are recorded by the magnet ring as $S_{1}, S_{2}, \ldots, S_{n-1}, S_{n}$, where the term $S_{i}$ is a representative settlement value relative to the foundation, and $i$ is the number of the settlement magnet ring.

The total crest PCS of the surface leveling points is $S_{t}$ (Figure 11). The relationship between the compression PCS of the fill body $\left(S_{f}\right)$ and that of the foundation $\left(S_{0}\right)$ can be written as

$$
\begin{aligned}
S_{f}= & \left(S_{n}-S_{n-1}\right)+\left(S_{n-1}-S_{n-2}\right)+\cdots+\left(S_{3}-S_{2}\right) \\
& +\left(S_{2}-S_{1}\right)+\left(S_{1}-S_{o}\right)=S_{n}-S_{o} .
\end{aligned}
$$

When the settlement plate is installed near the surface of the high fill, $S_{n}$ is approximately equal to $S_{t}$, and the crest PCS of the HFE $\left(S_{t}\right)$ can be written as

$$
S_{t}=S_{f}+S_{o} .
$$




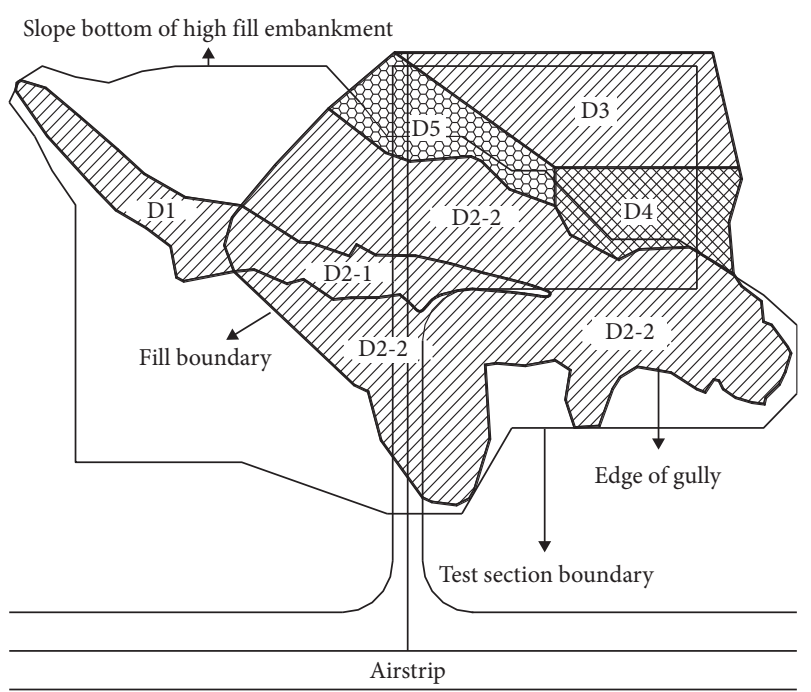

Graphic symbol

DCA DCE: $3000 \mathrm{kN} \cdot \mathrm{m}$
DCE: $6000 \mathrm{kN} \cdot \mathrm{m}$
DCE: $10000 \mathrm{kN} \cdot \mathrm{m}$

FIGURE 8: Foundation soil treatment with DC method.

For analyzing the PCS components of the HFE, the measured crest total PCS of the high fill $\left(S_{t}\right)$, the compression PCS of high fill body $\left(S_{f}\right)$, and that of the foundation soil $\left(S_{o}\right)$ of platform No. $2(1077.0 \mathrm{~m})$, No. $5(1107.0 \mathrm{~m})$, No. 6 $(1117.0 \mathrm{~m})$, and top of the high fill $(1158.5 \mathrm{~m})$ are shown in Figure 12.

Figure 12 shows the measured crest PCS with time at four elevations including No. 2, No. 5, and No. 6 platforms at different fill elevations (FEs) and the top of the HFE. CX1, CX-2, CX-3, and CX-4 represent the PCS values of the foundation soil $\left(S_{o}\right)$, as shown in Figure 12. The monitoring points of p2-2, p5-3, p6-4, and p3 represent the total PCS of the surface of the high fill $\left(S_{t}\right)$. The layout of the monitoring points is shown in Figures 9 and 10. From the above monitoring results, it can be concluded that during the construction stage, the crest settlement of different platforms increases rapidly with the high fill elevation; however, during the postconstruction stage, the crest PCS of HFE increases slowly and tends to be stable after one year. The crest PCS of the HFE consists of the compression of the fill body and that of the foundation induced by the fill load. The former part $\left(S_{f}\right)$ accounts for $20 \%$ to $40 \%$ of the total PCS while it is $60 \%$ to $80 \%$ of the total PCS $\left(S_{0}\right)$ for the latter. It can be concluded that $75 \%$ of the total PCS is induced by the deformation of the thick loess foundation under the high fill load. The settlement of the high fill body itself almost is completed during the construction stage. Only $25 \%$ of the total PCS occurs during the postconstruction stage. There is a large differential PCS on the surface of the HFE, which implies that the distribution of the original soil layers and fill thickness are uneven in the loess ravine. Besides, the compaction degree and water content of the fill materials are not homogeneous.
4.3. Influence of Fill Height on the PCS. Based on the monitoring data, the crest total PCS of the high fill $\left(S_{t}\right)$, the compression PCS of high fill body $\left(S_{f}\right)$, and that of the foundation $\left(S_{o}\right)$ are analyzed. The relationships between the $S_{t}, S_{f}, S_{o}$, and the thickness of the fill $(H)$ are shown in Figure 13. Among them, $S_{t 1}, S_{o 1}$, and $S_{f 1}$ are the monitoring results at the elevation of $1158.5 \mathrm{~m}$ during the completion period ( $T=342$ days); $S_{t 2}, S_{o 2}$, and $S_{f 2}$ are the monitoring results at the elevation of $1143.6 \mathrm{~m}$ during the intermission period ( $T=113$ days) in winter.

From Figure 13, the PCS of the high fill surface $\left(S_{t}\right)$, high fill body $\left(S_{f}\right)$, and foundation soil $\left(S_{o}\right)$ varies approximately linearly with the fill thickness $H$, as can be seen from the fitted relationships in Figures 13(a)-13(c). For a $10 \%$ increment in the fill thickness, the total PCS increases by $26 \%$, with three-quarters from the foundation and one-quarter from the fill body. The crest PCS of the high fill is $S_{t}=(0.11 \%-0.88 \%) H$, with an average $S_{t}=0.28 \% H$. The PCS of the fill body is $S_{f}=(0.03 \%-0.22 \%) H$, with an average $S_{f}=0.10 \% H$. The average value of the PCS ratio of the fill body is $S_{f}=0.38 \% H$, and the average value of the crest PCS ratio of the high fill is $S_{t}=1.27 \% H$. The measured PCS of loess HFE in this case is smaller than the average value of the reported cases [26-30]. This indicates that the control technology of the PCS, in this case, is better than previous projects.

4.4. Influence of Fill Rate on the PCS Rate. The average fill rate and the fill elevation with respect to the construction duration are shown in Figure 14. The average fill rate of the high fill varies from $0.2 \mathrm{~m} / \mathrm{d}$ to $1.4 \mathrm{~m} / \mathrm{d}$.

Suppose that the fill thickness is $H(\mathrm{~m})$, the total fill duration is $D$ (days), and the monitoring duration of the PCS is $T$ (days). During the completion period, the overall in situ monitoring duration is $T=217-342 \mathrm{~d}$, and the monitoring duration of the intermission period in winter is $T=113 \mathrm{~d}$. The average fill rate of the HFE below the monitoring point is defined as

$$
v=\frac{H}{D} .
$$

The average crest PCS rate $S_{t}^{\prime}(\mathrm{mm} / \mathrm{d})$ of the HFE, the average PCS rate of the foundation soil $S_{o}^{\prime}(\mathrm{mm} / \mathrm{d})$, and the average PCS rate of the fill body due to self-weight compression $S_{f}^{\prime}(\mathrm{mm} / \mathrm{d})$ are, respectively, defined as follows:

$$
\begin{aligned}
& S_{t}^{\prime}=\frac{S_{t}}{T}, \\
& S_{o}^{\prime}=\frac{S_{o}}{T}, \\
& S_{f}^{\prime}=\frac{S_{f}}{T} .
\end{aligned}
$$

Previous engineering experiences show that the instability of the high fill slope due to excessive PCS frequently occurs during the construction period when the fill rate is too high. The highest fill rate is $1-2 \mathrm{~m} / \mathrm{d}$ in a loess high fill 


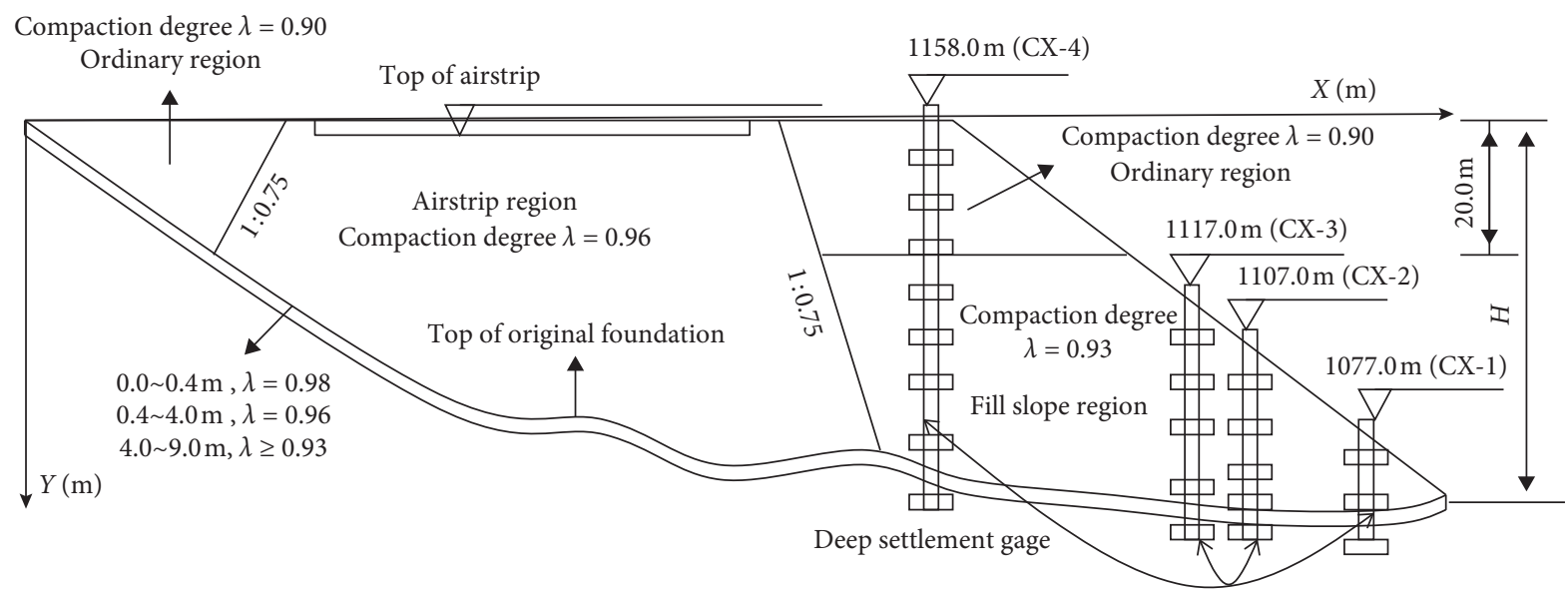

Figure 9: Compaction degree design of fill material in the test section.

TABle 6: Compaction methods and compaction degree standards of test fill.

\begin{tabular}{|c|c|c|c|c|}
\hline Location & $\begin{array}{l}\text { Below airstrip } \\
(\mathrm{m})\end{array}$ & Compaction method & Thickness of loose laying & Compaction degree \\
\hline \multirow{3}{*}{ Airstrip region } & $Y=0-1$ & $\mathrm{VC}+\mathrm{PC}$ & VC- $4 \times 0.35 \mathrm{~m}$, PC- $1.0 \mathrm{~m}$ & 0.98 \\
\hline & $Y=1-20$ & $\mathrm{VC}+\mathrm{PC}$ & $\mathrm{VC}-5 \times 0.40 \mathrm{~m}, \mathrm{PC}-1.5 \mathrm{~m}$ & 0.96 \\
\hline & $Y=20-H-20$ & $\mathrm{VC}+\mathrm{DC}$ & VC- $20 \times 0.40 \mathrm{~m}, \mathrm{DC}-6.0 \mathrm{~m}$ & \\
\hline \multirow{2}{*}{ Fill slope region } & $Y=0-20$ & \multirow{3}{*}{$\begin{array}{c}\text { VC ( } H \text { represents the height of fill body in } \\
\text { Figure } 8)\end{array}$} & $0.4 \mathrm{~m}$ & 0.90 \\
\hline & $Y=20-H-20$ & & $0.4 \mathrm{~m}$ & 0.93 \\
\hline $\begin{array}{l}\text { Ordinary } \\
\text { region }\end{array}$ & $\begin{array}{c}Y=0-1 \\
Y=1-H\end{array}$ & & $\begin{array}{c}3 \times 0.45 \mathrm{~m} \\
0.5 \mathrm{~m}\end{array}$ & 0.90 \\
\hline
\end{tabular}

project [31]. In order to comprehensively analyze the influence of the fill rate on the average PCS rate of high fill, the in situ monitoring results at the elevations of $1143.6 \mathrm{~m}$ and $1158.5 \mathrm{~m}$, in addition to the $4^{\text {th }}, 5^{\text {th }}$, and $6^{\text {th }}$ platforms of the fill slope, are discussed. The relationships between the average PCS rates $\left(S_{t}^{\prime}, S_{o}^{\prime}\right.$, and $\left.S_{f}^{\prime}\right)$ and the average fill rate $(v)$ are shown in Figures 15 and 16.

Figure 15 shows that the exponential relationship between $S_{t}^{\prime}, S_{o}^{\prime}, S_{f}^{\prime}$, and $v$ during the postconstruction stage, which can be written as

$$
\left\{\begin{array}{l}
S_{t}^{\prime}=0.0009 e^{15.935 v} \\
S_{o}^{\prime}=0.0009 e^{15.367 v} \\
S_{f}^{\prime}=0.0003 e^{15.825 v}
\end{array}\right.
$$

Figure 16 shows that, during the construction stage, when the average elevation of the fill reaches $1097.0 \mathrm{~m}\left(4^{\text {th }}\right.$ platform), $1107.0 \mathrm{~m}$ ( $5^{\text {th }}$ platform), and $1117.0 \mathrm{~m}\left(6^{\text {th }}\right.$ platform), an exponential relationship can be obtained between the PCS rate $S_{t}^{\prime}$ of the platform surface and the upper Earth fill rate $v$ :

$$
S_{t}^{\prime}=0.3 e^{3.0 v}
$$

Comparing Figures 15 and 16, the fill rate has a great influence on the PCS rate. The total PCS rate varies exponentially with the fill rate. For each $1 \%$ increment of the fill rate, the PCS rate increases by $7 \%$. When the fill rate is too high, it may cause an excessive PCS and the instability of the high fill slope.

4.5. Influence of Compaction Degree on the PCS. The in situ compaction degrees of the high fill in different domains and elevations are detected and compared with design values. The $S_{f} / H$ is defined as the vertical compression ratio of the high fill body, and the average compaction degree $\lambda$ is used to depict the integrated compaction degree of the fill body as follows:

$$
\lambda=\frac{\sum_{i=1}^{n} H_{i} \lambda_{i}}{\sum_{i=1}^{n} H_{i}}
$$

where $\lambda_{i}$ is the compaction degree of the fill body at different elevations and $H_{i}$ is the depth of the fill body with a certain compaction degree $\lambda_{i}$.

Based on the monitoring results at the elevations of $1143.6 \mathrm{~m}$ and $1158.5 \mathrm{~m}$, the monitoring domain is divided into three parts according to the average compaction degree. The relationship between $S_{f} / H$ and $H$ in the three parts with different average compaction degrees is shown in Figures 17(a) and 17(b). During the intermission period, the regression curves of the compression ratio of the high fill 


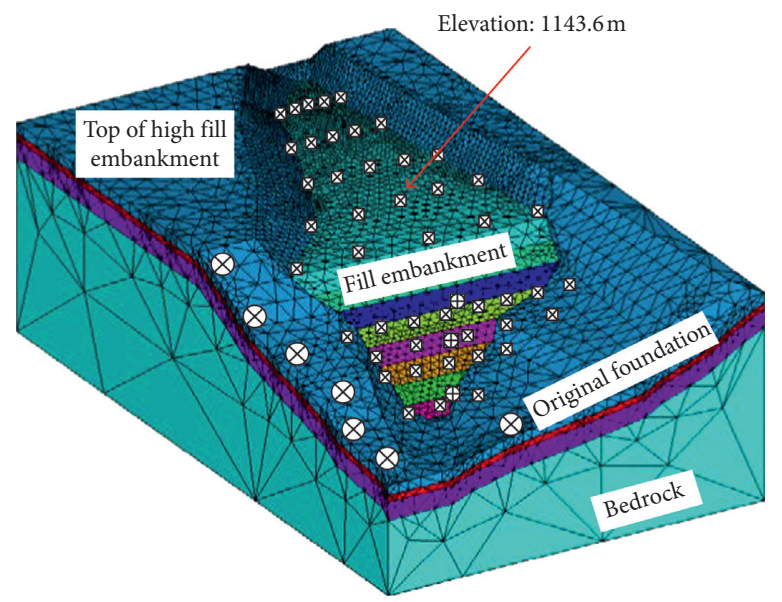

Deep settlement gage

$\otimes$ Bench mark

$\bigotimes$ Measuring point

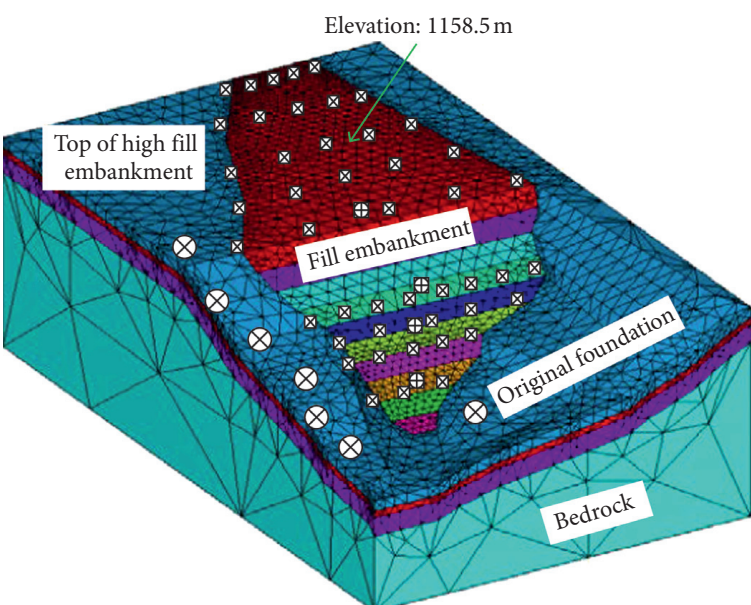

$\oplus$ Deep settlement gage

$\otimes$ Bench mark

$\bigotimes$ Measuring point

(a)

(b)

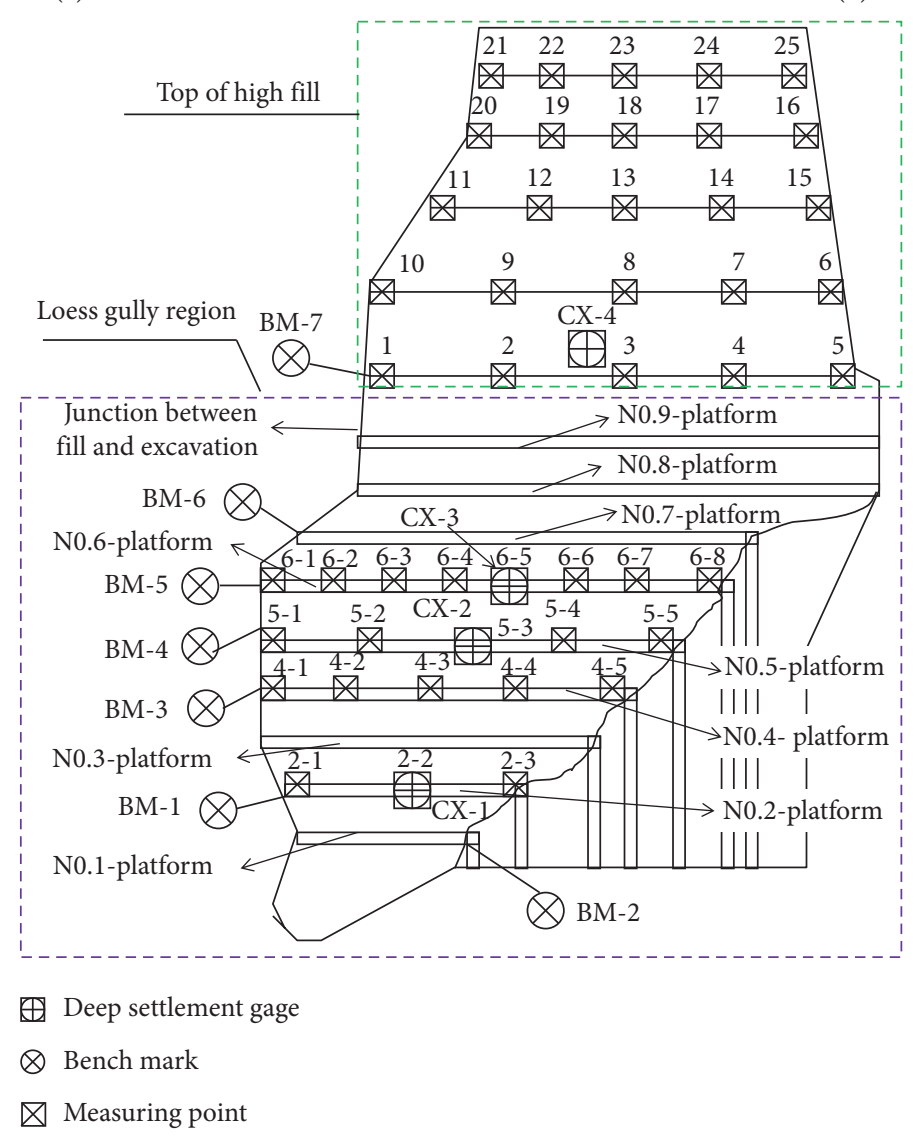

(c)

FIgURE 10: In situ monitoring points' layout of the test section of Lvliang Airport. (a) Monitoring points during the intermission period (Elevation: $1143.6 \mathrm{~m}$ ). (b) Monitoring points during the completion period (Elevation: $1158.5 \mathrm{~m}$ ). (c) Measuring points layout from the top view of the $3 \mathrm{D}$ model. 


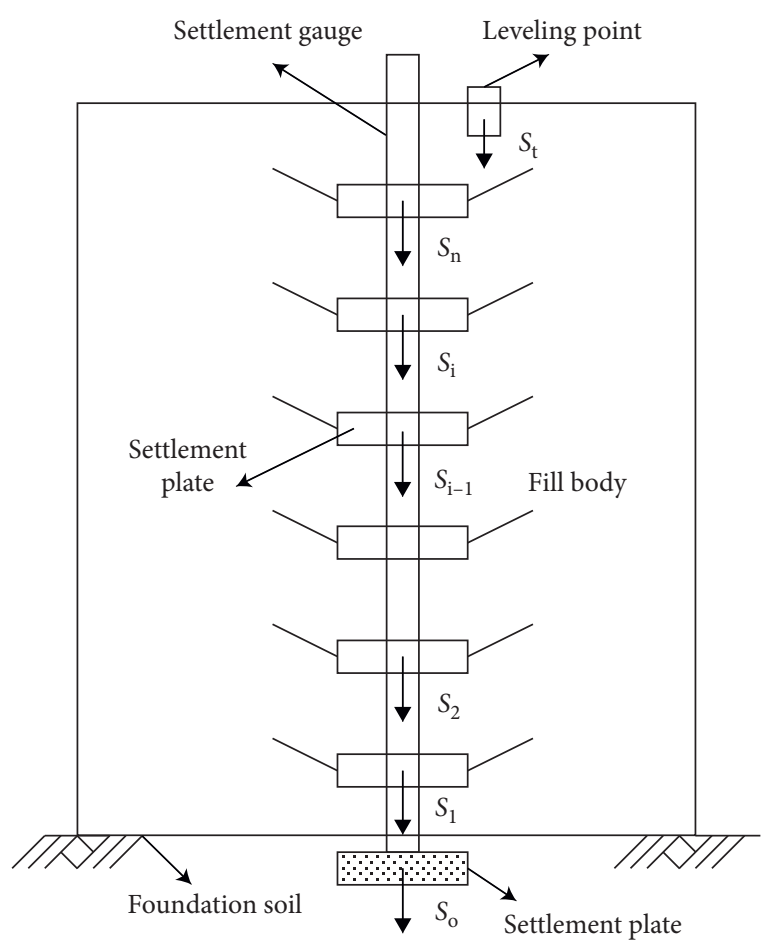

FIgURE 11: Layout of surface and deep-layered settlement monitoring points.

body with fill height under different average compaction degrees can be written as

$$
\begin{cases}\frac{S_{f}}{H}=18.545 H^{-0.880} & (\lambda=0.93), \\ \frac{S_{f}}{H}=7.8243 H^{-0.808} & (\lambda=0.96), \\ \frac{S_{f}}{H}=0.5177 H^{-0.141} & (\lambda=0.98) .\end{cases}
$$

During the completion period, the regression curves of the compression ratio of the high fill body with fill height under different average compaction degrees are as follows:

$$
\begin{cases}\frac{S_{f}}{H}=-0.0042 H+1.2242 & (\lambda=0.90), \\ \frac{S_{f}}{H}=-0.0044 H+1.1129 & (\lambda=0.93), \\ \frac{S_{f}}{H}=-0.0015 H+0.7980 & (\lambda=0.96) .\end{cases}
$$

From Figure 17, during the intermission and completion periods, the relationships between $S_{f} / H$ and $H$ is quite different. The former can be expressed as a power function, and the latter can be described as a linear equation. Besides, the value of the term $S_{f} / H$ in the intermission stage is higher than that in the completion stage because the PCS rate is unstable. The term $S_{f} / H$ gradually decreases to a stable value as the fill thickness increases within the same compaction degree domain. This indicates that the fill materials tend to undergo a hardening process under high-pressure conditions. The $S_{f} / H$ value gradually decreases as the compaction degree of the fill increases in different compaction degree domains. When the average compaction degree increases by $1 \%$, the value of $S_{f} / H$ decreases by $12 \%$. It is effective in reducing the PCS of the high fill and the foundation when their integrated compaction degree increases during the construction stage.

4.6. PCS Prediction Methods. In addition to providing stability standards for the HFE and to guide the starting time for the infrastructure construction on the top of the HFE, it is necessary to statistically analyze the PCS. Many mathematical methods are proposed to predict the PCS based on a large collection of measured data. Some of the commonly used predictive methods are Pearl and Gompertz Model [9, 10], hyperbolic model [32], exponential method and polynomial method [6], Asaoka and Weibull model [4], empirical method [7], and closed-form equation [8]. Based on the monitoring data, the hyperbolic, logarithmic, exponential, Gompertz, and Peal curves have also been used to predict the relationship between the PCS and the duration. The measured crest PCS of the HFE is set as regression analysis. The PCS and the PCS rate over the monitoring duration of the critical monitoring points are shown in Figures 18(a) and 18(b). The prediction results and prediction error of the crest PCS of the high fill with different models are shown in Figures 18(c) and 18(d). The regressive models and parameters are listed in Table 7.

However, except for the monitoring duration $(D)$, the factors that influence the PCS are not considered in the above regressive models. Hence, the models cannot reflect the fill height, fill rate, and the average compaction degree of the high fill. According to the previous monitoring results, the crest PCS of the high fill is closely related to the fill thickness $(H)$, average fill rate $(v)$, average compaction degree $(\lambda)$, and duration time $(D)$. Thus, based on equations (4)-(10), the empirical formula of the crest PCS of the high fill can be expressed as

$$
S=0.1305 e^{(15.25 v)}+\left(\frac{2 D}{43.5+0.705 D}-6.51 \lambda+6.64\right) H .
$$

A comparison between the monitored PCS and the predicted PCS with equation (11) is shown in Figure 18(e). The prediction error is less than $2 \%$, which well satisfies the requirements of major geotechnical engineering designs. The final crest PCS of the high fill, as calculated by the empirical equation, is shown in Figure 18(f). Taking the monitoring point 3 as an example, the predicted and measured PCS values are shown in Table 7. From the curves of PCS and PCS rate over time, the maximum PCS rate decreases from $5.23 \mathrm{~mm} / \mathrm{d}$ at the beginning to $0.23 \mathrm{~mm} / \mathrm{d}$ after 170 days, with the average PCS rate for all the monitoring points reduced to $0.09 \mathrm{~mm} / \mathrm{d}$. However, the crest PCS 


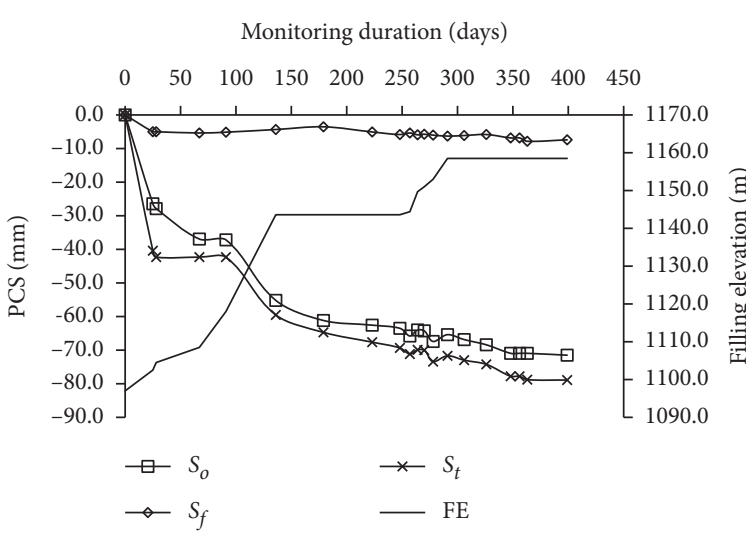

(a)

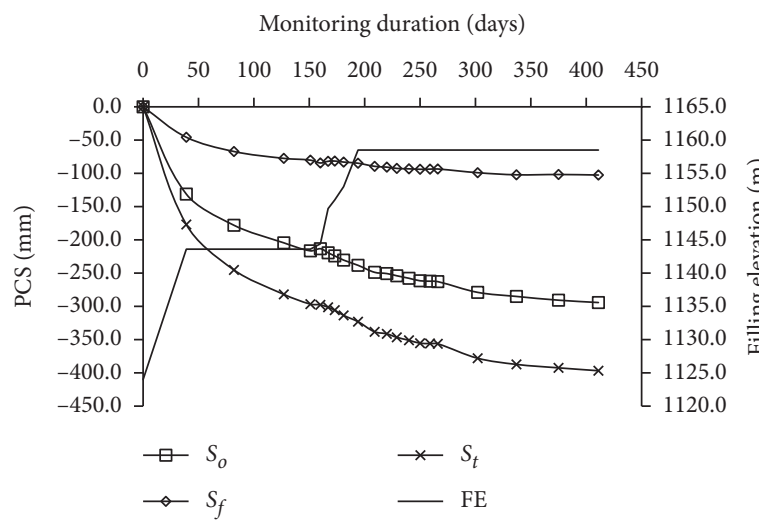

(c)

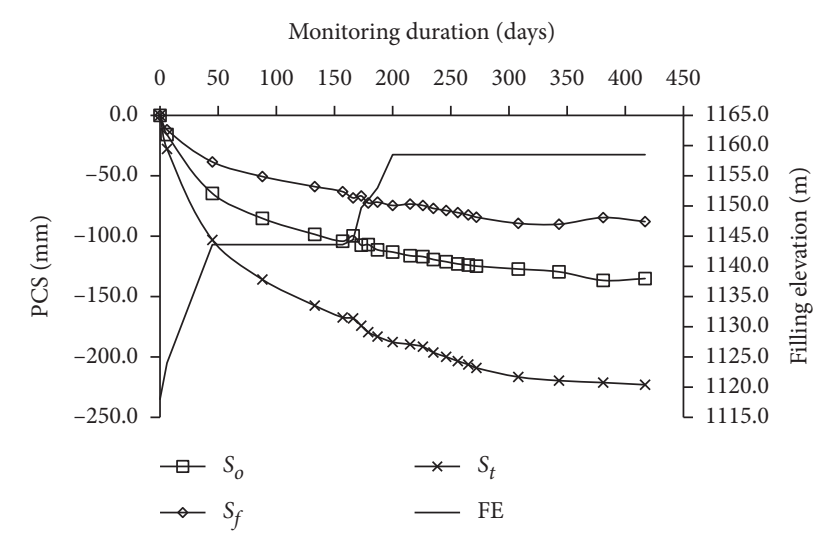

(b)

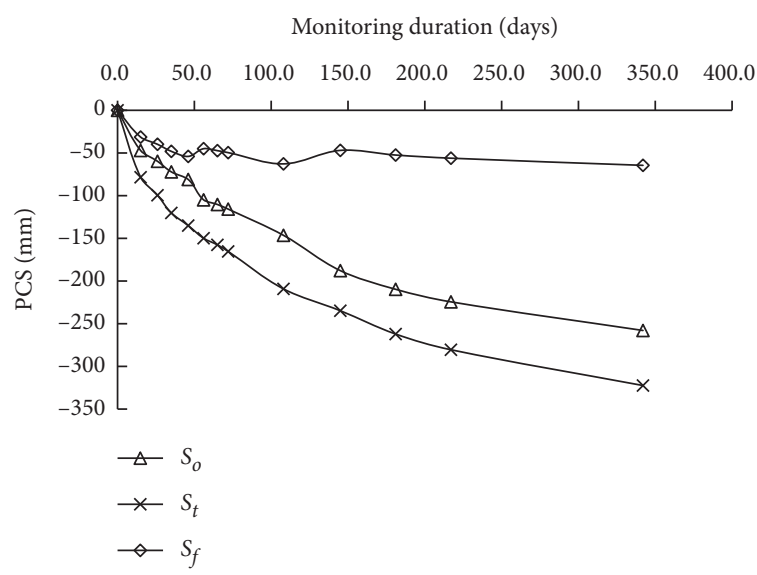

(d)

Figure 12: PCS versus monitoring date curves of surface and foundation. (a) No. 2 platform (1077.0 m). (b) No. 5 platform (1107.0 m). (c) No. 6 platform $(1117.0 \mathrm{~m})$. (d) Top of the high fill $(1158.5 \mathrm{~m})$.

rate of the HFE suddenly increases in July and September due to the occurrence of heavy rainfall, which results in the wetting deformation of the surface soil. The environment variations, including heavy rainfall infiltration and rising groundwater levels, also influence the PCS. Therefore, waterproofing and drainage measures must be considered in the loess HFE.

The crest PCS of the HFE increases and tends to stabilize over time. The relationship between the PCS and the time can be well described by the exponential and the Gompertz models. However, the proposed empirical formula (i.e., equation (11), including the factors that influence the PCS) can more accurately predict the crest PCS of the high fill. From Figure 18(f), the predicted final maximal PCS and differential PCS of the aircraft traffic link area and the high fill slope region during six years are $270-450 \mathrm{~mm}$ and $0.21 \%-0.31 \%$, respectively. However, the deformation control standard of the differential PCS is less than $0.15 \%$, which indicates that the maximal crest differential PCS of the high fill exceeds the allowable value.

\section{Standard for PCS Control of the HFE}

For controlling the crest PCS and the differential PCS of the HFE, according to MH/T 5027-2013, the allowable values of the PCS within 20 years should not exceed the values listed in Table 8.

Table 8 shows that the crest PCS and the differential PCS of the building areas on the HFE should be limited within $200 \mathrm{~mm}$ and $0.15 \%$, respectively. However, the measured maximal PCS, differential PCS during one year, and the final predicted crest PCS (see Figure 18(f)) exceed the allowable values. When the differential PCS exceeds the limits and the rainfall infiltrates into the surface soil at the same time, the cracks and doline between the boundary of the fill and the excavation are generated, as shown in Figure 19. These results indicate that the crest PCS and the differential PCS of the HFE do not meet the design requirements.

During the construction process, the water content, compaction degree, and fill rate of the compacted soil are detected. Based on the heavy compaction test of the fill, the optimal water contents of $Q_{3}$ and $Q_{2}$ loess are $13.27 \%$ and $12.23 \%$, respectively, while the maximum dry densities are 1.88 and $1.93 \mathrm{~g} / \mathrm{cm}^{3}$, respectively. The results are shown in Figure 20.

Taking the design area of $\lambda=0.90$ as an example, the measured compaction degree varies from 0.87 to 0.92 , with an average value of 0.89 , which is lower than the design value. The measured water content varies from $10.8 \%$ to 


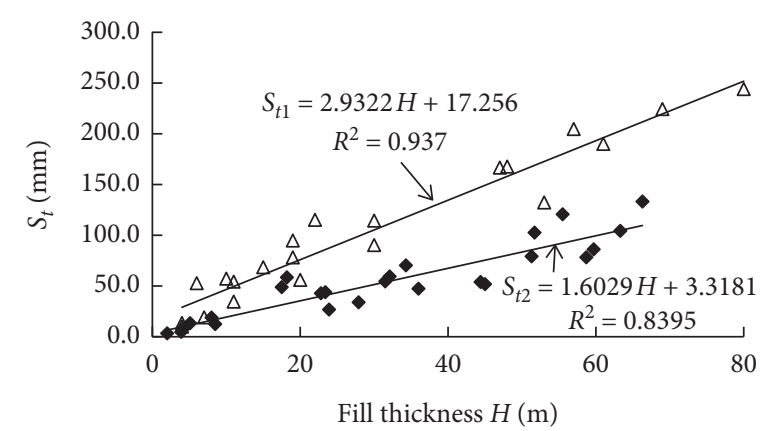

$\triangle$ Fill completion period

- Fill intermission period

(a)

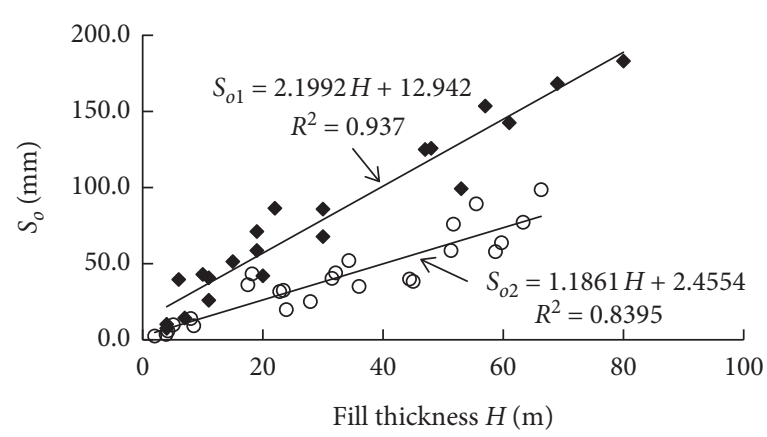

- Fill completion period

○ Fill intermission period

(b)

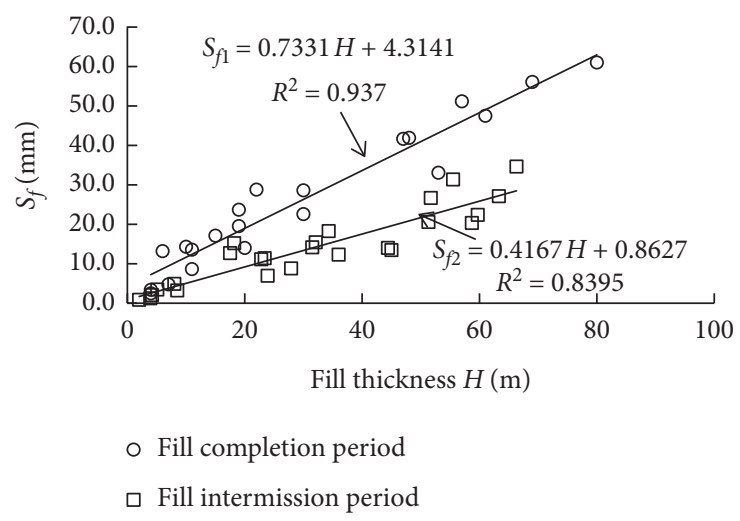

(c)

FIgURE 13: Relationship between $S_{t}, S_{o}, S_{f}$, and $H$. (a) Curves of $S_{t}-H$. (b) Curves of $S_{o}-H$. (c) Curves of $S_{f^{-}} H$.

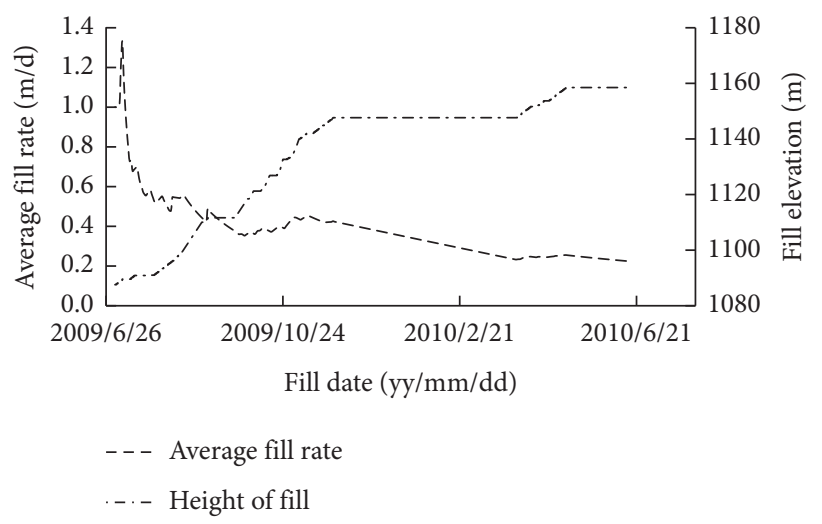

FIgURE 14: Fill process of the HFE.

$20.3 \%$, and the average value is $15.6 \%$, which is higher than the design value of $13.0 \%$. These results indicate that the actual compaction index of the HFE does not meet the design requirements.

From the above-measured data of the crest PCS and the construction parameters of the HFE, the following conclusions can be drawn:

(1) The actual compaction degree is $1 \%$ lower than the design value, and the actual water content is $20 \%$ on average higher than the design value. These may cause the measured crest PCS and the differential PCS to exceed their allowable values

(2) During the construction period, the maximal fill rate of $\mathrm{HFE}$ is $1.4 \mathrm{~m} / \mathrm{d}$, and the average fill rate is $0.45 \mathrm{~m} / \mathrm{d}$, which exceeds the allowable rate of $0.4 \mathrm{~m} /$ $\mathrm{d}$. The intermission time of each treatment with the DC method is less than 2 days (which is less than the recommended standard of 7 days). Therefore, the fill cannot be sufficiently compressed under selfweight 


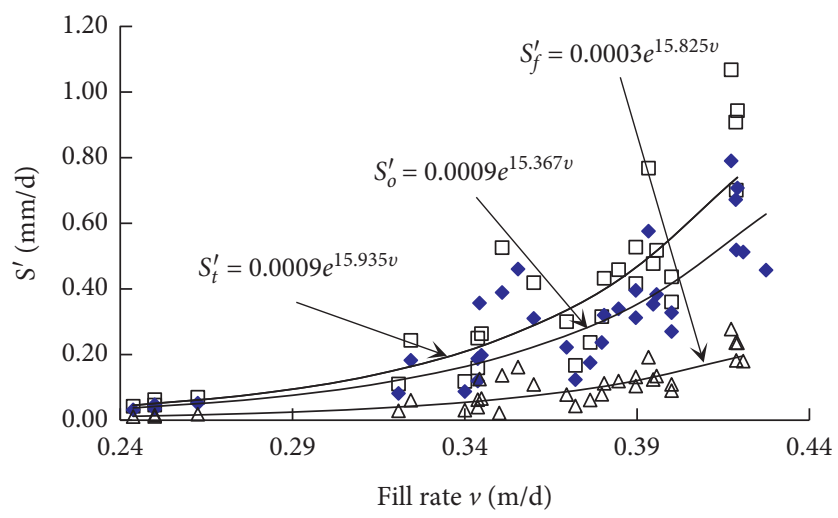

$\square$ Top of high fill

- Original foundation

$\triangle$ Fill body

FIgURE 15: Relationship between PCS rate and fill rate of the high fill surface.

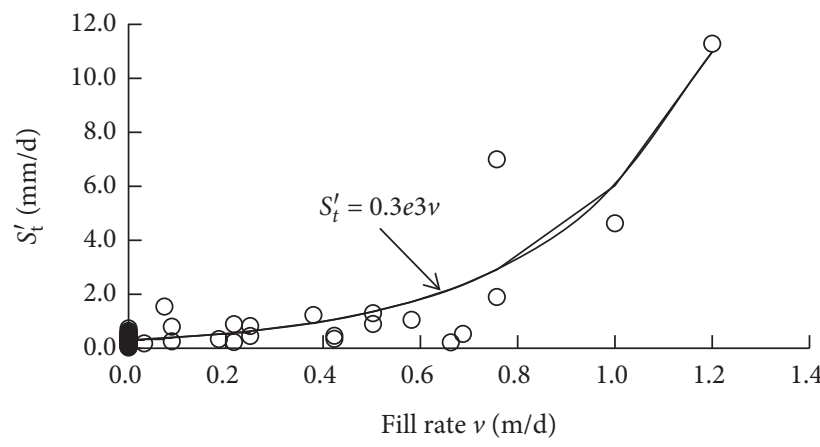

O Measured data

- Regression curve

FIgURE 16: Relationship between PCS rate and fill rate of the platform at the fill slope.
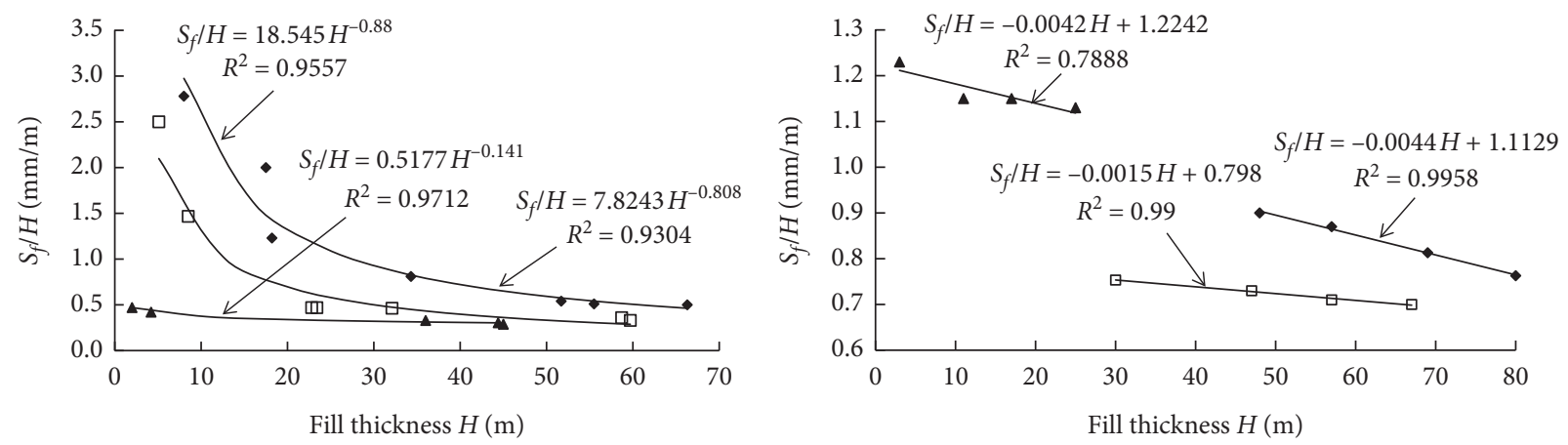

$$
\begin{aligned}
\text { - } \lambda & =0.93 \\
\text { } \lambda & =0.96 \\
\text { А } \lambda & =0.98
\end{aligned}
$$

$$
\begin{aligned}
\text { } \lambda & =0.90 \\
\text { - } \lambda & =0.93 \\
\text { } \lambda & =0.96
\end{aligned}
$$

(a)

(b)

FIGURE 17: Relationship between $S_{f} / H$ and $H$ under different average compaction degrees. (a) During the intermission period (1143.6 m). (b) During the completion period $(1158.5 \mathrm{~m})$. 


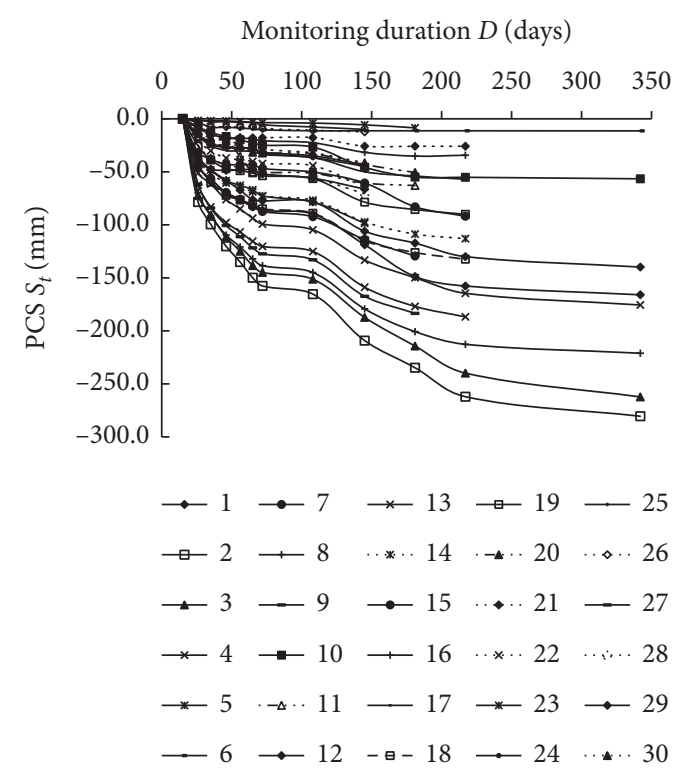

(a)

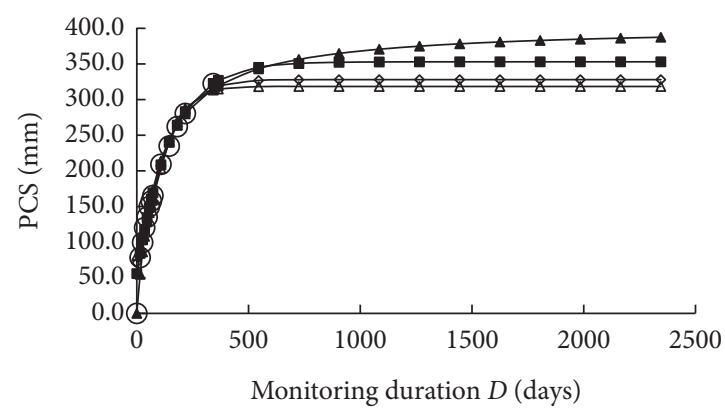

○ Measuement data $\rightarrow$ Gompertz curve

$\rightarrow$ Exponential curve $\rightarrow$ Peal curve

$\rightarrow$ Hyperbolic curve

(c)

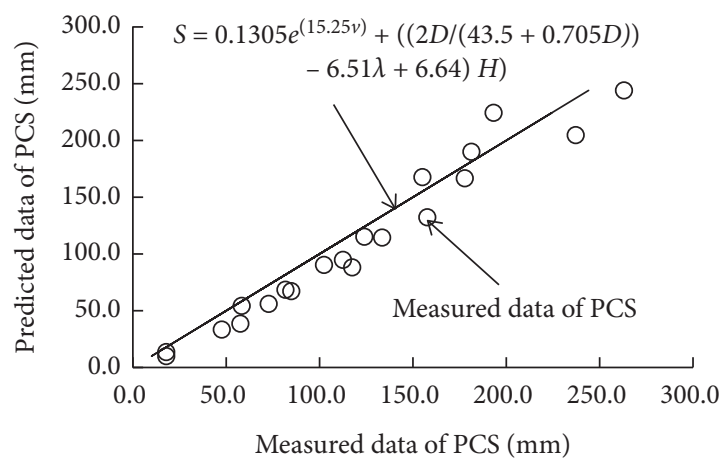

(e)

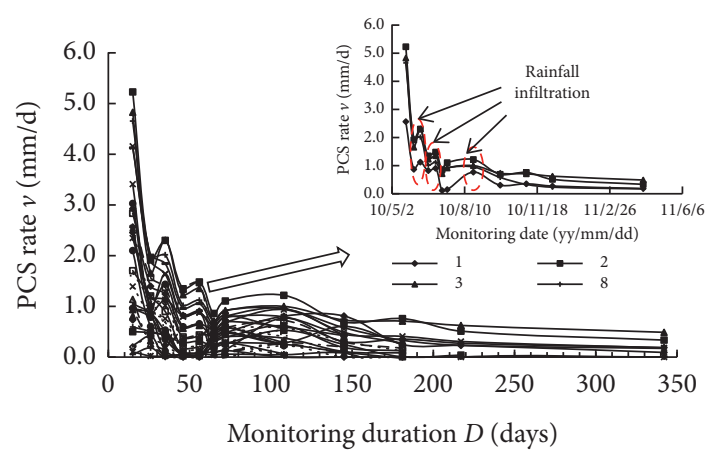

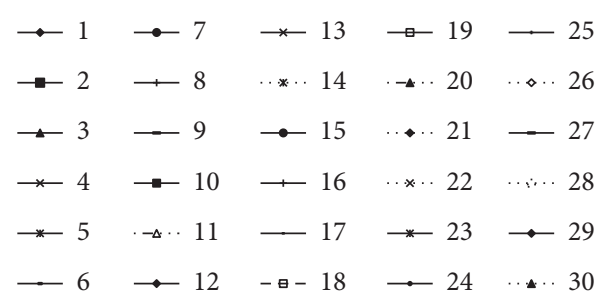

(b)

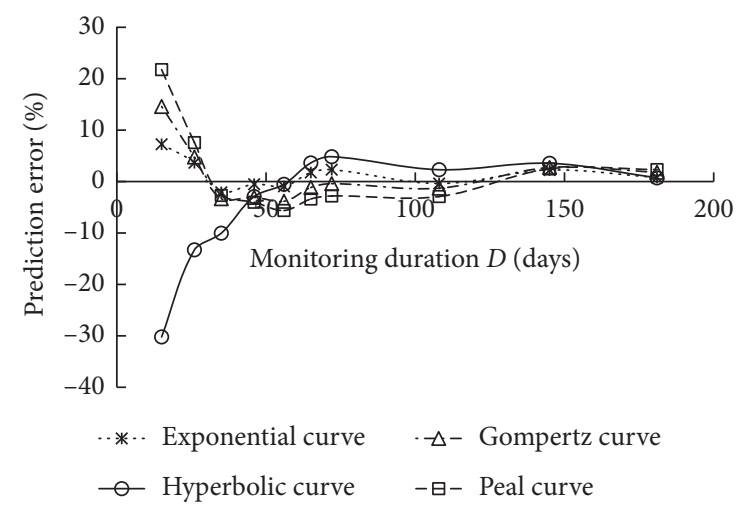

(d)

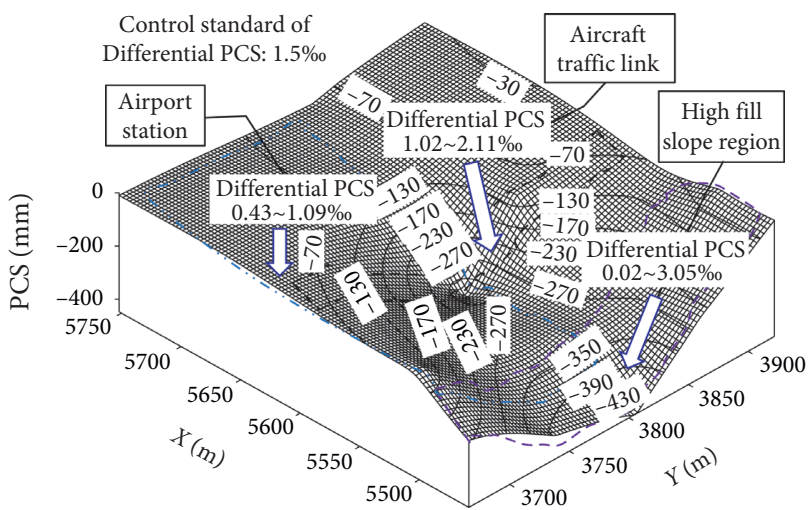

(f)

FIGURe 18: Crest PCS and differential PCS curves of the HFE. (a) PCS over monitoring duration. (b) PCS rate over monitoring duration. (c) Prediction of PCS. (d) Prediction error. (e) Comparison between prediction results and measured data. (f) Prediction PCS with the empirical method.

(3) The monitoring results show that the PCS of the foundation accounts for most of the total settlement. This probably results from the fact that the collapsibility of the deep loess layer is not eliminated in that the effective reinforcement depth of the DC is less than 5-9 $\mathrm{m}$ and the VSGP and PSCP exhibit poor 
TABLE 7: Regressive models of PCS and its parameters.

\begin{tabular}{|c|c|c|c|c|c|c|}
\hline \multirow{2}{*}{ Mathematical model } & \multirow{2}{*}{ Mathematical expression } & \multicolumn{3}{|c|}{ Regression parameter } & \multirow{2}{*}{ Predicted (mm) } & \multirow{2}{*}{ Measured $(\mathrm{mm})$} \\
\hline & & $a$ & $b$ & $c$ & & \\
\hline Exponential curve & $S=a-b e^{(-c D)}$ & 353.0 & 297.16 & 0.00667 & 322.6 & \\
\hline Hyperbolic curve & $S=D /(a+b D)$ & 0.2368 & 0.00248 & - & 315.2 & \\
\hline Gompertz curve & $S=e^{\left(c+a * b^{D}\right)}$ & -1.528 & 0.989 & 5.793 & 316.8 & 322.4 \\
\hline Peal curve & $S=c /\left(1+a e^{-b D}\right)$ & 2.931 & 0.0152 & 318.4 & 313.3 & \\
\hline Presented by authors & $S=f(v, \lambda, H, D)$ & - & - & - & 327.7 & \\
\hline
\end{tabular}

Note. In Table 7, the monitoring point 3 is taken as an example to compare the predicted and measured data $(H=80 \mathrm{~m}, D=342 \mathrm{~d}, \lambda=0.89, v=0.41 \mathrm{~m} / \mathrm{d})$.

TABLE 8: Allowable values of crest PCS and differential PCS of HFE in loess ravine.

\begin{tabular}{|c|c|c|c|c|c|}
\hline \multirow{2}{*}{ No. } & \multirow{2}{*}{ Areas } & \multicolumn{2}{|c|}{$S(\mathrm{~mm})$} & \multicolumn{2}{|c|}{ Differential PCS (\%) } \\
\hline & & Standard (20a) & Measurement (1a) & Standard (20a) & Measurement (1a) \\
\hline (1) & $\begin{array}{c}\text { Important or special building area: aircraft } \\
\text { traffic link, airport station }\end{array}$ & 100 & $132-242$ & 0.10 & $1.09-2.11$ \\
\hline (2) & General building area: high fill slope region & 200 & 323 & 0.15 & $0.02-3.05$ \\
\hline (3) & Traffic area & 300 & - & 0.20 & - \\
\hline (4) & Green area and other nonbuilding areas & 500 & - & - & - \\
\hline
\end{tabular}

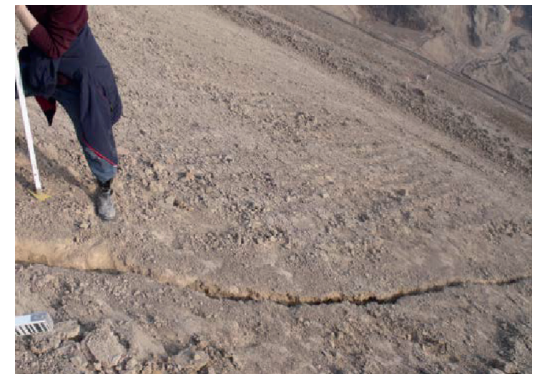

(a)

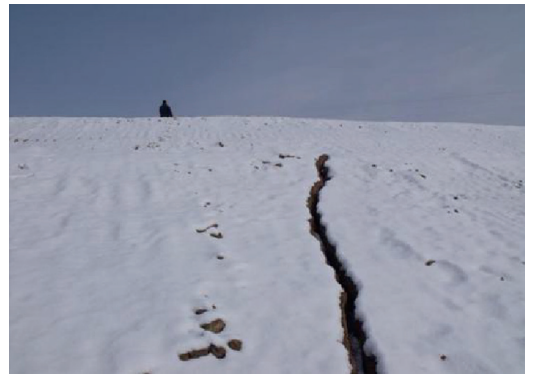

(b)

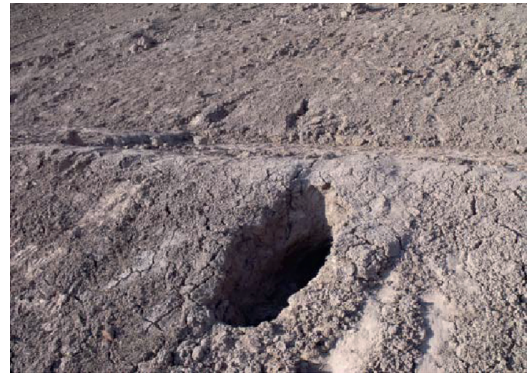

(c)

FIGURE 19: Cracks and doline between the boundary of the fill and the excavation. (a) Cracks between the fill and the foundation soil. (b) Cracks in the fill. (c) Doline in the fill.

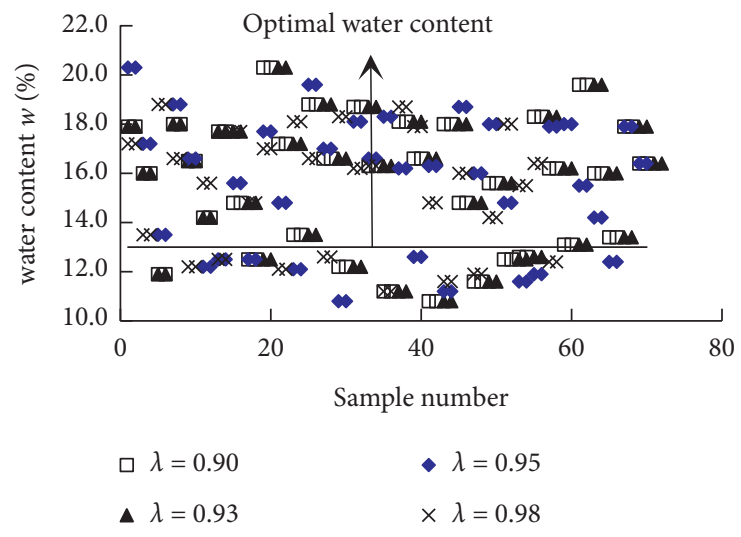

(a)

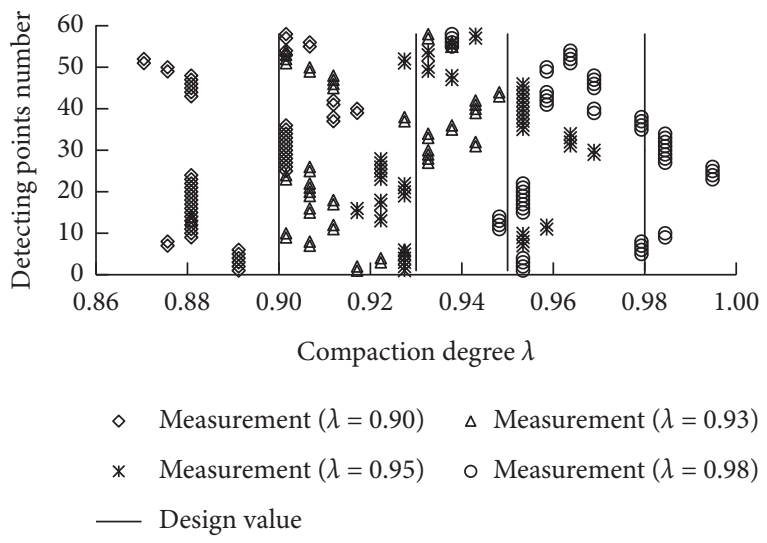

(b)

Figure 20: Measured value and design value of compaction degree and water content. (a) Measured water content. (b) Measured compaction degree. 
performance because of the high-water content in the foundation soil. It indicates that the stabilizers and admixtures should be mixed into compaction piles to reduce the water content and enhance the compression modulus of the foundation soil. Therefore, the commonly used CFG piles in soft soil foundations may be well suited

\section{Conclusions}

Based on a high fill airport over deep collapsible loess layers, the foundation treatment methods of the test section are assessed using field and laboratory tests. The PCS prediction methods are discussed based on the in situ monitoring results. The standards for controlling the PCS of the HFE constructed on the deep collapsible loess layer are proposed. The main conclusions are as follows:

(1) The average bearing capacities of the foundation reinforced by the DC, VSGP, PSCP, and VC+DC methods are $350 \mathrm{kPa}, 400 \mathrm{kPa}, 340 \mathrm{kPa}$, and $370 \mathrm{kPa}$, respectively, while the elastic moduli after reinforcement are 2.6, 2.3, 2.0, and 4.4 times those of the undisturbed soil, respectively. The effective treatment depth of the foundation by the DC method can reach 5-9 $\mathrm{m}$. While the VSGP method has a deeper treatment depth, it is prone to collapse during drilling. The PSCP method is more feasible in reinforcing the deep collapsible loess foundation.

(2) The PCS of the foundation accounts for approximately $75 \%$ of the total PCS and about $0.28 \%$ of the fill height while the PCS of the fill body itself accounts for a lower proportion. The crest PCS of the HFE increases linearly with the fill thickness. The PCS rate increases exponentially with the fill rate. When the average fill rate increases by $1 \%$, the PCS rate increases by $7 \%$ on average. However, when the fill rate is too high, it may cause excessive PCS and a negative effect on the stability of the high fill slope in the loess ravine.

(3) The average compaction degree of the fill body exhibits great influence on the PCS. When the average compaction degree increases by $1 \%$, the $S_{f} / H$ decreases by $12 \%$. Therefore, the PCS of the HFE can be effectively reduced by increasing the integrated compaction degree during the construction stage.

(4) For reducing the differential PCS, the VSGP method with the addition of lime/cement or CFG piles offers a suitable reinforcement treatment for deep collapsible loess, and the reinforcement depth should be more than $10 \mathrm{~m}$. The $\mathrm{VC}+\mathrm{DC}$ method is a favorable way to treat the fill body. The average compaction degree should be more than 0.93 , and the water content should be controlled between $11 \%$ and $15 \%$.

\section{Data Availability}

The monitoring data used to support the findings of this study are available from the corresponding author upon request.

\section{Conflicts of Interest}

The authors declare that they have no conflicts of interest.

\section{Acknowledgments}

The authors would like to extend their gratitude to the National Natural Science Foundation of China (Nos. 51678484 and 51778528) and the Research Fund of the State Key Laboratory of Eco-hydraulics in Northwest Arid Region, Xi'an University of Technology (2019KJCXTD-12), which funded this research, as well as the graduate students for their hard work in carrying out the testing.

\section{References}

[1] China Airport Construction Group Corporation, $M H / T$ 50272013. Code for Geotechnical Engineering Design of Airport, China Civil Aviation Press, Beijing, China, 2013.

[2] Z. D. Liu, Loess Mechanics and Engineering, Shaanxi Science and Technology Press, Xi'an, China, 1997.

[3] Y. Hu, Y. W. Ju, W. Z. Wang, and X. M. Zheng, "Study on settlement after construction for the high loess-filled embankment," Applied Mechanics and Materials, vol. 744-746, pp. 613-616, 2015.

[4] M. Inagaki, M. Nakano, T. Noda, M. Tashiro, and A. Asaoka, "Proposal of a simple method for assessing the susceptibility of naturally deposited clay grounds to large long-term settlement due to embankment loading," Soils and Foundations, vol. 50, no. 1, pp. 109-122, 2010.

[5] R. Ishikura, N. Yasufuku, and M. J. Brown, "An estimation method for predicting final consolidation settlement of ground improved by floating soil cement columns," Soils and Foundations, vol. 56, no. 2, pp. 213-227, 2016.

[6] L. Jia, J. Guo, and K. Yao, "In situ monitoring of the long-term settlement of high-fill subgrade," Advances in Civil Engineering, vol. 2018, Article ID 1347547, 9 pages, 2018.

[7] M. Kermani, J.-M. Konrad, and M. Smith, "An empirical method for predicting post-construction settlement of concrete face rockfill dams," Canadian Geotechnical Journal, vol. 54, no. 6, pp. 755-767, 2017.

[8] M. Kermani, J. M. Konrad, and M. Smith, "In situ short-term and long-term rockfill compressibility as a function of void ratio and strength of parent rock," Journal of Geotechnical and Geoenvironmental Engineering, vol. 144, no. 4, Article ID 04018009, 2018.

[9] X. Kong, "Research and application on the prediction method of Pearl Model of high-filling subgrade Settlement," International Congress and Exhibition "Sustainable Civil Infrastructures: Innovative Infrastructure Geotechnology", Springer, Cham, Switzerland, pp. 356-362, 2017a.

[10] X. Kong, "Research on the prediction method of Gompertz Model for high subgrade settlement," International Congress and Exhibition, Sustainable Civil Infrastructures: Innovative 
Infrastructure Geotechnology, Springer, Cham, Switzerland, pp. 363-369, 2017b.

[11] M. Mirjalili, S. Kimoto, F. Oka, and T. Hattori, "Long-term consolidation analysis of a large-scale embankment construction on soft clay deposits using an elasto-viscoplastic model," Soils and Foundations, vol. 52, no. 1, pp. 18-37, 2012.

[12] H. Li, J. Tao, L. Wei, and Y. Liu, "Explosive compaction technology for loess embankment settlement control: numerical simulation and field implementation," Acta Geotechnica, vol. 15, no. 4, pp. 975-997, 2019.

[13] H. B. Li, X. L. Zheng, Y. P. Sheng, and S. Ke, "Differential settlements of embankment treated by cement fly-ash gravel pile and sheet pile in freeway extension constructions," International Journal of Geomechanics, vol. 17, no. 11, Article ID 04017092, 2017.

[14] L. Li, H. Xiao, P. Ferreira, and X. Cui, "Study of a small scale tyre-reinforced embankment," Geotextiles and Geomembranes, vol. 44, no. 2, pp. 201-208, 2016.

[15] Y. Mei, C. M. Hu, and X. Y. Wang, "Experimental research on deep collapsible loess foundation treatment by dynamic compaction under super high fill," Applied Mechanics and Materials, vol. 256-259, pp. 129-138, 2012.

[16] R. K. Rowe and K.-W. Liu, “Three-dimensional finite element modelling of a full-scale geosynthetic-reinforced, pile-supported embankment," Canadian Geotechnical Journal, vol. 52, no. 12, pp. 2041-2054, 2015.

[17] E. M. D. Silva, J. L. Justo, P. Durand, E. Justo, and M. VázquezBoza, "The effect of geotextile reinforcement and prefabricated vertical drains on the stability and settlement of embankments," Geotextiles and Geomembranes, vol. 45, no. 5, pp. 447-461, 2017.

[18] C. Wang, B. Wang, P. Guo, and S. Zhou, "Experimental analysis on settlement controlling of geogrid-reinforced pileraft-supported embankments in high-speed railway," Acta Geotechnica, vol. 10, no. 2, pp. 231-242, 2015.

[19] K. Wang, Y. Zhuang, H. Liu, and H. Xiao, "Multilayered lowstrength geogrid-reinforced piled embankment," Geotechnical Research, vol. 5, no. 4, pp. 231-246, 2018.

[20] C. Zhang, G. Jiang, X. Liu, and Z. Wang, "Deformation performance of cement-fly ash-gravel pile-supported embankments over silty clay of medium compressibility: a case study," Arabian Journal of Geosciences, vol. 8, no. 7, pp. 4495-4507, 2015.

[21] G. Zhu and Y. Han, "Treatment of collapsible loess foundation," IOP Conference Series: Earth and Environmental Science, IOP Publishing, vol. 218, no 1, Article ID 012006, Bristol UK, 2019.

[22] M. Esmaeili and H. Khajehei, "Mechanical behavior of embankments overlying on loose subgrade stabilized by deep mixed columns," Journal of Rock Mechanics and Geotechnical Engineering, vol. 8, no. 5, pp. 651-659, 2016.

[23] H. Zhang, J. K. Chen, S. W. Hu, and Y. Z. Xiao, "Deformation characteristics and control techniques at the shiziping earth core rockfill dam," Journal of Geotechnical \& Geoenvironmental Engineering, vol. 142, no. 2, Article ID 04015069, 2016.

[24] Y. Wang, "Analysis of control measures for settlement of differences on the problems of highway subgrade widening," Open Journal of Civil Engineering, vol. 5, no. 2, pp. 149-153, 2015.

[25] M. Tashiro, T. Noda, M. Inagaki, M. Nakano, and A. Asaoka, "Prediction of settlement in natural deposited clay ground with risk of large residual settlement due to embankment loading," Soils and Foundations, vol. 51, no. 1, pp. 133-149, 2011.

[26] G. He, Q. Li, F. Hong et al., "Analysis of post-construction settlement of Transformation substation high fill foundation in mountainous areas," Journal of Architecture and Civil Engineering, vol. 24, no. 4, pp. 45-49, 2007.

[27] Li Peng, Study on Settlement of High Embankment and Composite Foundation Properties, Changan University, Xi'an, China, 2005.

[28] H. Liu, P. Li, and Z. Zhang, "Prediction of the post-construction settlement of the high embankment of Jiuzhai-huanglong airport," Chinese Journal of Geotechnical Engineering, vol. 27, no. 1, pp. 90-93, 2005.

[29] Q. C. Wang, Speed Railway Civil Engineering, Southwest Jiaotong University Press, Chengdu, China, 2000.

[30] C. Xie, Study on the Behavior and Deformation of the Ground Compacted with Crushed Stone of High Fill Block in the Outgoing Airport, Chengdu Univerisity of Technology, Chengdu, China, 2001.

[31] C. Zhu and N. Li, "Ranking of influence factors and control technologies for the post-construction settlement of loess high-filling embankments," Computers and Geotechnics, vol. 118, Article ID 103320, 2020.

[32] Q. Q. Zhang, S. C. Li, F. Y. Liang, M. Yang, and Q. Zhang, "Simplified method for settlement prediction of single pile and pile group using a hyperbolic model," International Journal of Civil Engineering, vol. 12, pp. 179-192, 2014. 